\title{
La Arquidiócesis de Bogotá y LA APARICIÓN DE NUEVOS ACTORES SOCIALES EN EL CONTEXTO URBANO, 1900-2000
}

\author{
María Teresa Cifuentes Traslaviña \\ Leopoldo Prieto Páez
}

\section{PRESENTACIÓN}

Este capítulo busca mostrar la manera como la Arquidiócesis de Bogotá fue ajustando a lo largo del siglo XX y los inicios del XXI la aplicación de las orientaciones de la Iglesia frente a la cuestión social y el impacto que tuvo en el acercamiento a los trabajadores, tanto en la organización sindical como en estrategias para acompańar a la población vulnerable afectada por condiciones socioeconómicas precarias y más adelante, como víctima del conflicto social y armado.

Abordar la presencia de la Arquidiócesis de Bogotá y el enfoque social en un período tan extenso (todo el siglo XX y los inicios del XXI), en medio de transformaciones estructurales de la sociedad colombiana (y de manera más significativa en la capital), es complejo en la medida que los cambios en las relaciones

económicas, sociales, culturales y políticas desbordan cualquier intento de periodización para seguir el rastro y profundizar la manera como la Arquidiócesis fue haciendo la lectura de la realidad y ajustando su presencia en el campo social.

Se pretende mostrar la forma como las trasformaciones urbanas que experimentó la ciudad, cada vez a ritmos más acelerados, agenciaron la aplicación de obras e instituciones que buscaban aplicar las directrices de la acción social católica y la doctrina social de la Iglesia, haciendo un particular énfasis en la organización y la atención de la "población obrera" (mote con el cual se conoció a la masa trabajadora indistintamente de su ocupación durante gran parte del siglo) y su posterior influjo en el desarrollo del sindicalismo católico. 
A partir de los años sesenta se evidenciará el complejo modo en que acelerados cambios en la sociedad y en la misma Iglesia determinarían el camino de la acción social. La Arquidiócesis no fue ajena a momentos de crisis, a cuestionamientos y a intentos de renovar, no solo la interpretación de la realidad sino de ajustar su discurso y su acción a las nuevas problemáticas que se fueron presentando. Esto es cierto especialmente desde finales de los años setenta con la profundización del conflicto social y armado, el cual ha desembocado en los últimos años en un aumento desmesurado de sus víctimas que buscan en Bogotá un refugio que les permita salvar sus vidas, aunque no siempre en las condiciones más dignas. En suma, se presenta una rápida mirada al papel jugado por la Arquidiócesis en relación con estos temas, sin agotar la posibilidad de análisis más profundos y con nuevos enfoques que enriquezcan la reflexión.

\section{CONSIDERACIONES PRELIMINARES}

$\mathrm{Al}$ referirse a la Bogotá de comienzos del siglo XX, se suele afirmar que la capital colombiana era apenas un pueblo grande. Algunos autores han tratado de matizar esta tajante caracterización, relevando la complejidad de los procesos y las dinámicas internas en las que se vio envuelta la ciudad durante estos años. En ese sentido, Germán Mejía asegura que "para 1910 [Bogotá] ya tenía el potencial necesario para convertirse en lo que hoy denominan los especialistas una urbe moderna" (Mejía, 2002, p. 480). Esto quiere decir que las bases para construir el desarrollo subsiguiente, con todos los cambios que esto implica, ya habían sido echadas durante los primeros años del siglo XX. La adecuación urbanística, la construcción de nuevos equipamientos, la extensión de redes de servicios públicos, la adaptación de zonas para viviendas y en general la búsqueda de un hábitat urbano, son aspectos que ya eran perceptibles en la ciudad por estos años y que ciertamente corresponden a la vida de una urbe en crecimiento y difícilmente a la de un "pueblo".

Más allá de la cuestión semántica, lo que resulta significativo resaltar es que los problemas a los cuales se enfrenta la ciudad en la primera mitad del siglo XX son en absoluto los de un caserío con pretensiones de ciudad. De hecho, cada vez están más presentes problemas típicos de una ciudad moderna, como por ejemplo el crecimiento vertiginoso de los moradores. El censo de 1912 contabilizó en la ciudad un total de 121.217 habitantes, para 1938 se registraban 330.312 almas, en 1951 ya moraban 715.250 personas, población 


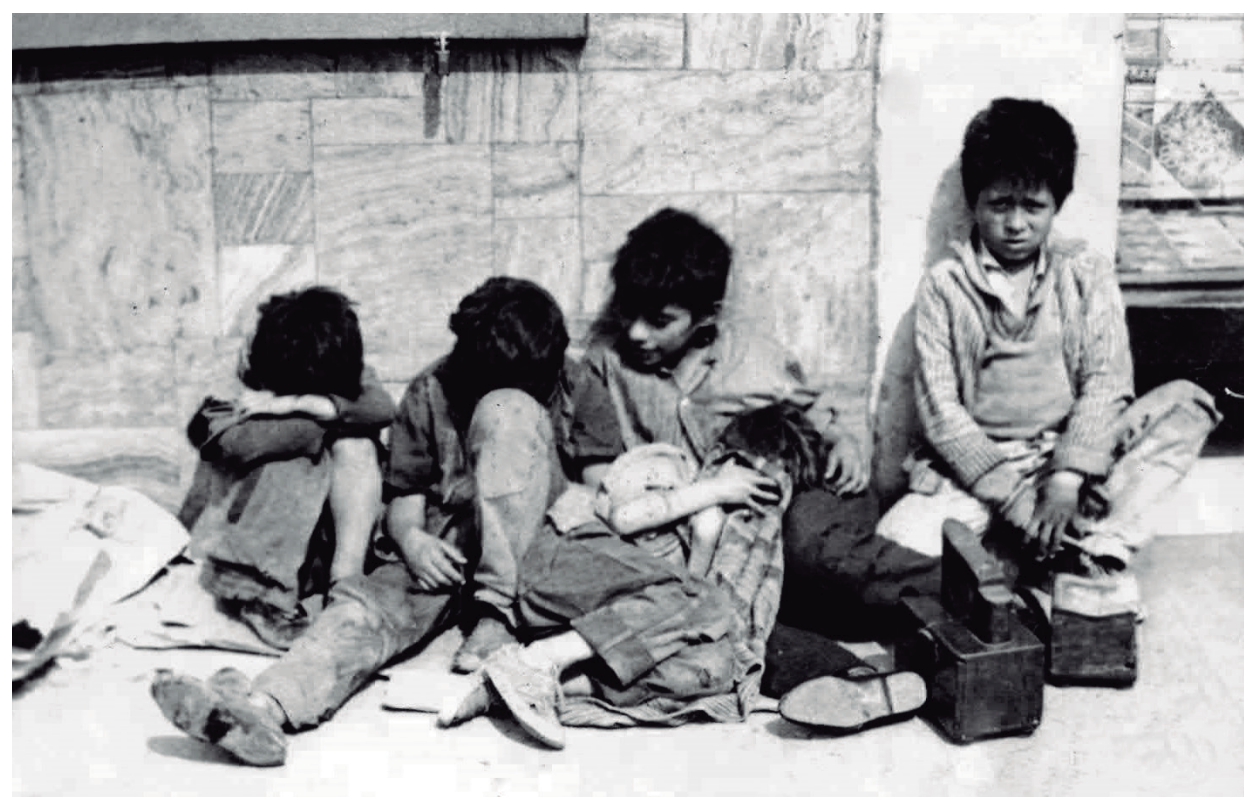

Figura 1. Anónimo. (1982). Focos de miseria: barrio El Socorro. Bogotá: Archivo de El Catolicismo. (Sin catalogar).

que se cree aumentó en 1956 a la, para entonces escandalosa, cifra de un millón de habitantes. Este ritmo de crecimiento se mantendrá por lo menos hasta la década de 1990 cuando se registran 6.500.000 habitantes, correspondiendo a una tasa de crecimiento por encima de cuatro por ciento anual durante varias décadas de la primera mitad del siglo XX (Zambrano, 2007, p. 89).

Estos datos resultan pertinentes en la medida que el crecimiento sostenido, vertiginoso y masificado enfrentó a los centros urbanos a retos inéditos que con frecuencia desbordaron la capacidad estatal, como por ejemplo la oferta de servicios urbanos, ramo en el cual se evidenciaron durante más de medio siglo, serias carencias en la calidad de su prestación. Un informe sobre el acueducto de la ciudad era diciente de la situación a la que se enfrentaban los pobladores por estos ańos:

El informe ofreció un respaldo a la percepción colectiva: las aguas eran impotables. Más que eso, eran un atentado a la salud. En las muestras se encontró "una fuerte cantidad de materias orgánicas" una "enorme cantidad de microbios" y la simple inspección notaba el marcado olor "fecaloide" (Vargas y Zambrano, 1988, p. 42). 
El caso de la vivienda era aún más paradigmático pues los índices de escasez crecieron conforme crecía la población, de suerte que un sinnúmero de organizaciones buscaron ofrecer un lugar habitable dentro de la ciudad, desde el ambicioso urbanizador pirata, hasta la oferta pública de vivienda de calidad, pasando por las organizaciones de beneficencia, todos se encontraban en el mismo escenario. En un primer momento denominados "barrios obreros" y luego convertidos en urbanizaciones piratas, en general los pobladores más pobres fueron quienes debieron afrontar los rigores de la falta de habitación en la ciudad. Un hecho ocurrido en 1927 es diciente de lo que se viene señalando:

[...] durante 1927 se realizó una huelga de inquilinos. El sindicato Central Obrero de Bogotá que lo respaldaba, afirmaba que un obrero necesitaba de quince días de trabajo para pagar el arriendo de un mes, es decir 50\% del ingreso, una situación escandalosa para una ciudad que había sido patriarcal y donde el techo no tenía valor (Vargas y Zambrano, 1988, p. 26).

Aunque no fuera una regla, la construcción barrial y la lucha por los servicios públicos convocaba a diferentes sectores a organizarse y a reivindicar derechos por un hábitat digno. De hecho, al lado de las preocupaciones estatales estaban presentes los movimientos de comunidades religiosas, quienes siguiendo las directrices del catolicismo social realizaron acciones que pretendían contribuir a subsanar las dificultades enfrentadas por muchos de los bogotanos y cuyo medio de acción implicaba formas de asociación y movilización organizada. Algunas de ellas muy elementales, como la clásica caridad cristina, que gracias a los oficios de instituciones de beneficencia atendió amplios grupos de pobres, enfermos y huérfanos a quienes les ofreció un refugio temporal y atención allí donde el Estado estuvo ausente.

Pero también hubo formas de organización más complejas, por ejemplo el Círculo de Obreros del padre José María Campoamor, al cual se definía como "una sociedad -no política- que tiene por objeto atender el perfeccionamiento de la clase obrera en el orden económico, intelectual, moral y religioso" (citado en Hernández, 2010), cuya obra más emblemática fue la construcción del barrio Villa Javier, convertido ahora en:

[...] la demostración concreta de los beneficios que podría traer a los obreros el sistema de ahorro y sistema de alquiler de vivienda, al tiempo que se ofrecía como prueba, también concreta, 
de la acción social de la iglesia católica, en seguimiento de las encíclicas papales (Saldarriaga, 1994, p. 76).

La cuestión social era señalada como un aspecto determinante en el accionar de la Iglesia católica en este periodo, fundamentalmente por la presencia del comunismo y su influjo negativo sobre la enorme población de trabajadores industriales que irrumpían en el escenario urbano de la mayor parte de las ciudades de Europa occidental y Norteamérica. No obstante, en Colombia se confundía el comunismo con otros "males" que permeaban la sociedad y no podía ser de otro modo, pues en estas primeras décadas Colombia era:

un escenario muy inhóspito para el desarrollo del moderno industrialismo con la excepción de algunas pocas ciudades como Medellín, Bogotá, Barranquilla y Cali, en las cuales tampoco logró germinar un capitalismo vigoroso que abarcara a toda la población del país (Kalmanovitz, 2010, p. 199).

Es decir, percibían el comunismo tan pernicioso como otras formas de pecaminoso actuar, pero dado el estado tan incipiente de una corriente ideológica de este talante en el país, tal suerte de amenaza constante se unía en una amalgama de razones que eran objeto de atención por parte de la institución eclesiástica. Así, las malas condiciones de vida de los sectores más pobres de la población, al que indistintamente se le llamaba obrero, era un caballo de batalla en el que se evidenciaban estos elementos, de manera que cuando los políticos, urbanistas o sacerdotes en Bogotá hablaban de intervenir las barriadas pobres, lo hacían sustentados en dos aspectos fundamentales: la higiene y la moral.

El primer factor era evidente, pues la falta de las condiciones más elementales de salubridad en la vivienda de grandes sectores de población en situación de miseria, aumentaba el índice de mortalidad básicamente porque las epidemias golpeaban allí en primer lugar y de manera más fuerte. El segundo factor implicaba "la muerte del alma", la concentración promiscua de individuos, sin consideraciones de edades y de sexos, en espacios reducidos, oscuros y malolientes. Esto determinaba entre otras cosas que estas personas:

[...] no teniendo comodidad alguna en su hogar, [procuraran] permanecer en él el menos tiempo posible, y lo mismo puede decirse de sus hijos. La familia no se forma [...] ni en el orden físico, 
ni en el orden moral, puede decirse que la familia que vive en tales condiciones no tiene hogar (citado en Colón, 2013).

De todas maneras, resulta sorprendente la forma como estos problemas en cierto modo, hacían parte inherente al desarrollo del modelo capitalista. En Londres la Comisión para la Vivienda de la Clase Trabajadora entregó un informe en 1884 en el que hacía las siguientes consideraciones:

Pregunte a los hombres y mujeres que viven en estas pocilgas si están casados y lo único que obtendrá será una sonrisa. Nadie sabe. A nadie le importa. Nadie espera que deban estarlo [...] El incesto es común: no hay vicio ni sensualidad que despierte sorpresa ni llame la atención [...] Lo único que no les hace caer en el comunismo es la desconfianza, no la virtud. Las prácticas más viles son vistas con la mayor indiferencia. En una de las calles hay 35 [casas], de ellas 32 son burdeles (citado en Hall, 1996, p. 27).

La defensa de la moral estrechamente ligada a la preocupación por la posible y peligrosa seducción de ideas políticas "perjudiciales" en los grupos obreros de la ciudad, determinó adicionalmente que amplios escenarios de la vida cotidiana fueran objeto de intervención tanto por el Estado como por grupos e instituciones regidas bajos los preceptos morales de la Iglesia. La razón era una: los valores se encontraban en franco peligro. Por este motivo fueron condenadas prácticas típicas de la vida de los sectores obreros como el consumo de alcohol, pues promovía "el abandono de los valores religiosos [...] [lo que] tendría devastadoras consecuencias" (Archila, 1991, p. 174). Pero la cuestión no se restringió al castigo de los beodos, sino que se extendió a otras prácticas comunes de uso del tiempo libre por parte de los trabajadores como los juegos de azar, el baile, los cines y los libros.

Es pertinente anotar en este punto que existió una consonancia entre los intereses religiosos y los empresariales, pues la moral y la productividad, dos valores fundamentales de la sociedad de la primera mitad del siglo XX, se veían seriamente amenazados en aquellos escenarios de "pecado"y "holgazanería". Un buen ejemplo sobre la manera como los esfuerzos se unían para rechazar conjuntamente estas malas prácticas se encuentra en algunos textos escolares como la Cartilla antialcohólica, en la que se exponen los más sentidos temores frente a esa población "obrera” y se promueve a través de la formación de los niños, las pautas de comportamiento esperables de los individuos dignos de respetabilidad. 
En la mencionada cartilla se compara la vida de dos hermanos, el uno rebelde y pernicioso obrero de una fábrica, el otro digno y sumiso ingeniero del acueducto. Mientras aquel se hunde en los vicios que le llevan a la ruina y acaban con la unión familiar, el otro es ascendido en su empresa y exclama exultante ante esta noticia: “¡oh! ¡Mil gracias! Me esforzaré por cumplir con mis deberes ¡Cuánto gusto van a tener mis padres y toda mi familia con esta noticia!" (Calvo y Saade, 2002, p. 96). Mientras su hermano es ascendido, el borrachín es despedido de la fábrica en la cual trabaja y vocifera la siguiente réplica: “ ¡Me dejan sin trabajo! Porque bebo una que otra copa ¡Miserables! Voy a promover una huelga porque estos ricos deben saber lo que es el pueblo" (Calvo y Saade, 2002, p. 96). Es interesante resaltar que el alcoholismo que le convierte en miserable, desadaptado y pernicioso, también le lleva a protestar en contra de sus patronos, una práctica condenada y en el contexto que estudiamos, también temida.

Este sencillo relato pedagógico es diciente sobre la construcción social de los valores y virtudes encomiables así como de antivalores y formas de comportamiento condenables, por un lado la insubordinación política unida al inconformismo social o laboral eran indicadores de la "falta de juicio", mientras que la obediencia, la lealtad y el orden hacían parte de las virtudes devenidas por gracia de dios, la patria, el padre y la empresa (Calvo y Saade, 2002). El papel de la empresa no es gratuito y tampoco la elección de la fábrica y el rol del trabajador como escenarios de la parábola moderna, cuyo trasfondo se insinuaba ya desde finales del siglo XIX, advertido por el papa León XIII, que había asegurado que las ideas socialistas "perjudican a los obreros mismos [...] pervierten los deberes del Estado, e introducen una completa confusión en el orden social" (León XIII, 1891).

En realidad la preocupación era patente. Si bien a comienzos del siglo XX se encontraban aún en estado primigenio, la población de trabajadores industriales y junto a ella la más numerosa clase trabajadora, esa población asalariada del sector de servicios y del sector manufacturero pronto iba ir creciendo en número y demandas por "la fuerza dinamizadora del crecimiento industrial de los años diez y veinte resultado del despegue de la economía cafetera", que impactó la vida de las ciudades y las relaciones de producción de una forma hasta ahora inédita en Colombia. Pero más aún, durante las dos décadas subsiguientes, 1930 y 1940, el crecimiento "estuvo marcado por una impresionante recuperación industrial. Colombia registró en estos años la tasa de crecimiento anual más grande de toda América Latina y también la más alta de su historia: 8,5\% anual" (Kalmanovitz, 2010, pp. 202-204). 
Este ritmo de crecimiento no solo hacía que las ciudades se desarrollaran aceleradamente, como ya hemos visto, sino que aumentó el enfrentamiento con los patronos, tanto por intereses contrapuestos en el ámbito laboral como por reivindicaciones elementales de mejores condiciones de trabajo y de existencia. Desde muy temprano la Iglesia católica apoyó algunas de estas iniciativas, entre otras cosas porque estas asociaciones mutuales -como fueron llamadas en aquel primer momento- con frecuencia combinaban objetivos de solidaridad, reivindicación social y cohesión religiosa (Archila, 1991).

En este contexto se entiende la irrupción de iniciativas como las de José María Campoamor, que a través de la organización obrera bajo los preceptos del catolicismo social, buscó estimular el ahorro y la ayuda a grupos trabajadores, promoviendo ciertas acciones de intervención (escuelas nocturnas para adultos, escuela diurna para jóvenes, el barrio Villa Javier, la Caja de Ahorros) que contaron con el apoyo decidido de la jerarquía capitalina y de un sector del clero. Pero más común fue que "al abrigo del paternalismo que impregnaba la época, y por impulso clerical o empresarial, proliferaron las organizaciones asistencialistas en los primeros decenios de este siglo" (Archila, 1991, p. 216), cuyo papel fue altamente relevante, como el asilo de San José para nińos desamparados o el asilo de San Antonio, así como ciertos hospitales, de común regentados por miembros de comunidades religiosas.

Es preciso mencionar que las organizaciones de apoyo a los trabajadores como los patronatos, centros obreros y congregaciones, cumplieron un papel fundamental en la construcción de formas modernas de defensa de los derechos de los trabajadores como los sindicatos, mucho más que las organizaciones de caridad y asistencialismo, las cuales estaban supeditadas a los vaivenes de la liquidez financiera del benefactor de turno. En efecto "para los años veinte las antiguas sociedades mutuarias, los clubes políticos del artesanado e incluso sociedades secretas teosóficas o espiritistas, sirvieron de albergue para que los primeros asalariados expresaran su descontento con el orden vigente" (Archila, 1991, p. 232). De esos primeros escenarios se deprendieron organizaciones sindicales que paulatinamente fueron adquiriendo protagonismo a lo largo de la década de 1920, momento en el que el volátil panorama social de agitación política y formas de presión como la huelga alcanzaron notoriedad.

Cuando en 1913 se decide impulsar la Acción Social Católica era claro que por el tipo de interés en los pobres y en los necesitados, pero sobre todo en los obreros, el clero iba a tener un papel protagónico en el desarrollo de la organización social de esta población, un aspecto que se constató en varias re- 
giones del país aunque con matices significativos en esos primeros años, como por ejemplo la presencia más activa de las comunidades religiosas en zonas como Antioquía y mucho más marginal en ciudades como Barranquilla. La forma que caracterizó este tipo de intervención pastoral específicamente en Bogotá es objeto de examen en el siguiente apartado.

\section{Acción Social Católica y organización obrera}

Dentro de las preocupaciones pastorales que la Arquidiócesis de Bogotá tenía al iniciar el siglo XX, es notorio el afán por dar forma a la Acción Social Católica y con ella, acercarse al mundo del trabajo, el cual mostraba signos de cambio al transitar de una economía eminentemente rural al desarrollo de una incipiente industria y por supuesto, a la conformación de un nuevo de grupo social: los trabajadores urbanos, casi todos venidos de las áreas rurales.

Estas inquietudes le llegaban a la Iglesia colombiana desde el Vaticano, a donde veían en los cambios ocurridos en la segunda mitad del siglo XIX (como la consolidación del capitalismo y la formación de la clase obrera en Europa y Estados Unidos), una situación nueva frente a la cual el distanciamiento de los trabajadores de la Iglesia era significativo. El interés del socialismo de organizar y conducir a los trabajadores a la lucha por sus derechos, estimuló en parte ese distanciamiento. Esta situación llevó a la Iglesia a idear formas de acercarse a los obreros y a sus familias.

En el seno del catolicismo europeo se desarrollaron acciones de carácter asistencial pero también organizativo que buscaban paliar la suerte de los trabajadores. Fueron muchos los laicos y clérigos que generaron una armazón práctica y teórica que sentó las bases del catolicismo social. Al finalizar el siglo, la encíclica Rerum Novarum publicada en 1891, condensó el pensamiento de la Iglesia en el campo social y orientó la acción de los católicos para responder a la explotación de los trabajadores y al rumbo que tomaban las organizaciones que los aglutinaban, las cuales sustraían a miles de ellos de la influencia de la Iglesia.

Respondiendo al mandato de Roma, los obispos colombianos en las conferencias episcopales de 1913 y 1916 publicaron amplios documentos donde expresaron la preocupación del Papa por el rumbo que tomaba la confrontación entre patronos y obreros. También enfatizaban que solamente mediante la vuelta al cristianismo, bajo la acción restauradora de la Iglesia, se lograría poner freno al anarquismo y a las falsas promesas del socialismo. 
Planteaban que "mediante la acción y la organización de la propaganda católica [había] que ganarse al pueblo haciéndolo cooperar en la obra de la restauración cristiana" (Conferencias Episcopales, s.f., p. 51). Los documentos explicaban los fines y los medios de la Acción Social Católica, como la creación de instituciones de carácter económico que buscaran mejorar la condición de las clases trabajadoras, la instrucción y la educación cristiana y el aprendizaje de artes y oficios. Asimismo, se orientaba a los prelados para crear en cada diócesis y en las parroquias la Acción Social Católica y fundar en los seminarios la cátedra semanal, indicándoles un listado de las obras que podían instaurarse según las circunstancias de cada lugar:

Oratorios festivos para niños. - Escuelas de artes y oficios. Cajas de ahorro escolares. - Cajas dotales para jóvenes. - Cajas de ahorro para obreros. - Sociedades de temperancia. - Bibliotecas populares. - Círculos de la juventud católica. - Círculos y patronatos para obreros. - Restaurantes escolares. - Casa de refugio y talleres para la preservación de niñas y jóvenes. - Sociedades cooperativas de agricultura. - Sindicatos. - Cajas rurales y bancos agrícolas (Conferencias Episcopales, s.f., p. 61).

Es interesante observar que antes de las orientaciones de la Conferencia Episcopal sobre la Acción Social Católica, en la Arquidiócesis de Bogotá circulaban publicaciones como la revista La Iglesia, en donde se difundían artículos dando a conocer los objetivos y el sentido de dicha estrategia de la Iglesia. El arzobispo Bernardo Herrera Restrepo anexaba bibliografía sobre el tema como:

Ketteler: su obra social, su acción, sus orientaciones; La acción social; Los esclavos cristianos y la acción social de la Iglesia; Sobre la esclavitud y el trabajo; Tratado de economía social; El paro forzoso; Trabajo barato; El problema de la mujer; religión y Socialismo y patronos y obreros. (La Iglesia, 1910, pp. 668-691)

En varios números de La Iglesia es recurrente la inclusión de textos donde diferentes autores, en particular jesuitas, comentaban los documentos pontificios sobre la cuestión social y reseńaban la actividad de los católicos en este campo en países como Alemania, Francia, Suiza, Italia e Inglaterra. También señalaban que la caridad es curativa pero las obras sociales son preventivas y llamaban a estudiar el entorno para saber qué tipo de obras eran propicias en 
cada caso. Insistían en la creación de cátedras especiales de economía política y sociología católica (La Iglesia, 1916, pp. 109-118).

El padre Mario Valenzuela daba explicaciones acerca de las causas del socialismo, el comunismo y el anarquismo, a la vez que planteaba su versión de qué era y qué pretendía cada una de estas corrientes, llamando a fomentar el espíritu cristiano entre patronos y obreros (La Iglesia, 1919, pp. 25-26). El padre Amadeo Álvarez reflexionaba sobre el derecho de propiedad sustentándolo en el derecho natural y en las necesidades de la vida colectiva y del hombre. Denunciaba que el bolchevismo en Rusia avanzaba en la destrucción de la religión y la moral, e indicaba que Colombia no se podía "dormir" y que era necesario usar la caridad para con el proletariado y reunir a la clase obrera en sociedades de beneficencia ( $L a$ Iglesia, 1920, pp. 270-279).

De lo anterior se deduce que hubo un real interés en difundir, por parte de la Arquidiócesis, el pensamiento social de la Iglesia y dar a los sacerdotes y los pocos laicos que tenían acceso a los documentos citados, herramientas conceptuales y modelos de organización para emprender las actividades con los pobres a quienes denominaban obreros y en general con los grupos sociales que necesitaban el apoyo en otros campos como la educación, la formación para el trabajo, el empleo, la vivienda y por su supuesto la formación religiosa y moral según los cánones de la Iglesia. Con esto pretendían cerrar el paso al enemigo, que según el discurso manejado por la Iglesia, era poderoso y sagaz para enredar a los trabajadores, tal como caracterizaban al socialismo.

Para hacer efectivas las orientaciones de Roma y de la Conferencia Episcopal, en marzo de 1917 se constituyó en la Arquidiócesis el Directorio de Acción Social, constituido por monseñor Leonidas Medina, obispo auxiliar de Bogotá, el padre José María Campoamor y el señor Hernando Holguín y Caro (La Iglesia, 1917, p. 65).

\section{ORGANIZACIONES DE AYUDA SOLIDARIA Y ASISTENCIAL}

Hasta bien entrado el siglo XX, en Bogotá subsistían un tipo de organizaciones heredadas del siglo anterior conocidas como mutualismo, manejadas en su mayoría por los párrocos que promovían entre los fieles el aporte a un fondo que era utilizado para ayuda de servicios funerarios de los más pobres (Vélez y Montoya, 2001). Entre estas están la Sociedad Católica fundada en 


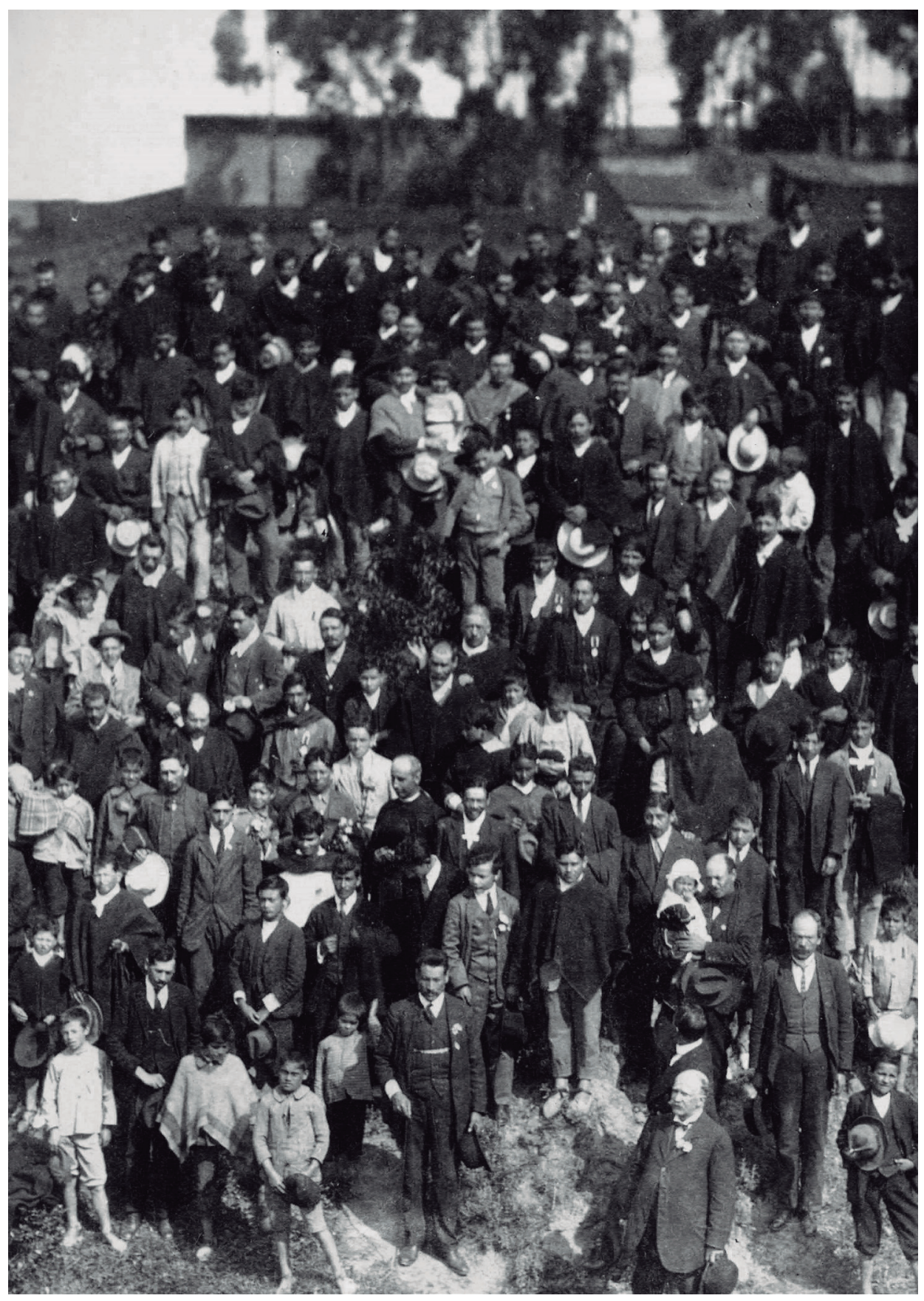

Figura 2. Anónimo. (s. f.). El padre José María Campo Amor reunido con los obreros de Villa Javier. En: Alfredo Iriarte. (1991). 80 años de la Caja Social de Ahorros. Socios de la Historia Universal. Bogotá: Litografía el Arco. p. 55. 
Bogotá en 1838 y la Sociedad de Caridad, fundada en julio de 1864. El requisito para ingresar era profesar la religión católica (Cortés, 2007). Además de artesanos, al mutualismo pertenecían habitantes pobres de las ciudades que requerían apoyo económico para sufragar gastos en situaciones que sobrepasaban las limitaciones corrientes. En general la institución católica ejercía influencia sobre estas organizaciones.

La presencia activa de católicos tanto laicos como clérigos y religiosos, se expresaba en organizaciones que buscaban prestar asistencia a diversos sectores pobres de la ciudad. En octubre de 1857 un grupo de laicos fundó en Bogotá la Sociedad de San Vicente de Paúl, institución de origen francés que tenía como lema: "abrazar al mundo con una red de caridad". Es de anotar que desde el periodo de dominación espańola, pero particularmente con la Constitución de 1886, el Estado entregó a la Iglesia el manejo de la asistencia social, por eso era usual encontrar a religiosos dirigiendo asilos, hospicios y hospitales. En 1894 monseñor Manuel María Camargo inició la obra del Niño Jesús a favor de la infancia desamparada, conocida posteriormente como la "Asociación de la Santa Infancia". Es preciso señalar la concepción asistencial y paternalista con que la Iglesia orientaba estas instituciones.

Aunque el espíritu de la Acción Social Católica tendía a generar mecanismos de organización en los que los asociados tuvieran mayor participación, fue difícil superar el carácter asistencial en la vinculación de la Iglesia en el trabajo con los pobres. Entre las primeras y más significativas instituciones fundadas a principios del siglo XX y que respondían a estos propósitos orientadores, estaba el ya mencionado Círculo de Obreros del padre José María Campoamor, del cual basta con agregar que fue tomado como modelo de intervención por parte de la Iglesia. De hecho, una amplia reseña en la revista La Iglesia menciona esta obra como el ejemplo más encomiable en términos de avance en ayuda hacia los más pobres, reconociendo la obra de Campoamor como una de las estrategias más nobles en relación con atención a los obreros (La Iglesia, 1915, p. 159). El artículo describía los programas con los que contaba el círculo en relación con la economía, la moralidad, la instrucción y la religión, los cuatro ejes básicos sobre los que se sustentaba la obra del sacerdote jesuita, tal como se muestra en el cuadro que se reproduce a continuación (La Iglesia, 1915, p. 168): 


\begin{tabular}{|c|c|c|c|}
\hline & Socios & Fines & Medios \\
\hline \multirow[b]{2}{*}{$\sum_{0}^{\infty}$} & \multirow{2}{*}{$\begin{array}{l}\text { Obreros } \\
\text { Obreras }\end{array}$} & Economía & $\begin{array}{l}\text { Caja de ahorros } \\
\text {-Pensiones para la vejez } \\
\text { Mutualidad para enfermos } \\
\text {-Para caso de defunción } \\
\text { Cooperativa de consumo } \\
\text {-De construcción de casa } \\
\text { Bolsa de trabajo }\end{array}$ \\
\hline & & Instrucción & $\begin{array}{l}\text { Restaurantes Escolares } \\
\text { Escuelas semi-internados } \\
\text { Talleres } \\
\text { Colonia agrícola de niña } \\
\text { Ropero escolar } \\
\text { Institutos nocturnos } \\
\text { Conferencias } \\
\text { Prensa } \\
\text { Bibliotecas }\end{array}$ \\
\hline \multirow{2}{*}{ 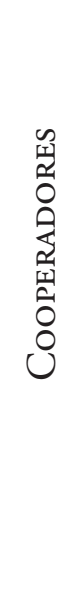 } & \multirow[t]{2}{*}{ Señores } & Moralidad & $\begin{array}{l}\text { Juegos de movimiento } \\
\text { Excursiones } \\
\text { Batallón infantil } \\
\text { Cinematógrafo } \\
\text { Teatro } \\
\text { Estudiantina }\end{array}$ \\
\hline & & Religión & $\begin{array}{l}\text { Preceptos de la Iglesia } \\
\text { Obras de misericordia } \\
\text { Congregación de San } \\
\text { Francisco Javier }\end{array}$ \\
\hline
\end{tabular}


En el mismo volumen se hablaba de la Sociedad de Santa Orosia, fundada en 1906 por el presbítero Guillermo Ángel Olarte con el ánimo de "estimular en los obreros al trabajo asiduo, y fomentar entre ellos la unión cristiana y el hábito de economía" (La Iglesia, 1915, p. 169). Esta sociedad también funcionaba como ente de mutuo apoyo -particularmente en situaciones de enfermedad- aunque durante el tiempo que funcionó también creó una caja de ahorros y el Asilo de la Infancia Desamparada. Se condenaban algunas prácticas típicas de sobreexplotación por parte de los patronos, como por ejemplo la costumbre de pagar el salario semanal los domingos con el ánimo de obligar a los trabajadores a ir este día para realizar labores que no eran pagadas. En cualquier caso, el Arzobispo señalaba una y otra vez la importancia de la instrucción de la masa obrera en los valores y preceptos de la moral católica, atendiendo a las directrices definidas en la llamada Acción Social.

Otras obras también inscritas en los fines de la Acción Social son las de la madre Margarita Fonseca, fundadora de las Siervas de Cristo Sacerdote, quienes iniciaron su labor con la Casa Protectora dirigida a "nińas obreras" fundada en 1909. Una contemporánea de la madre Margarita señalaba:

[...] junto con el doctor Carlos Cortés Lee, sacerdote diocesano, la señora Ana Vergara de Samper y la señora Saturia Álvarez de García sostenían unas 50 niñas de la clase obrera. [...] estas niñas tenían clases intelectuales en la mañana y en las horas de la tarde les enseñaban tapetes, bordados, alpargatas, tejidos, sombreros de fique (citado en Del Buen Pastor, s.f.).

La madre Margarita expresaba en unos versos el sentido de la obra señalada:

Es de toda la Acción Social Católica

Que en esta sociedad se ha establecido

Esta obra de protección para las jóvenes

Tan sencilla y humilde en sus principios,

Una pequeña piedra del cimiento

Del grandioso y magnífico edificio;

Una gota no más de la corriente

De Acción social que trata en nuestro siglo

De mejorar la suerte del obrero

$\mathrm{Y}$ de acercar los pobres a los ricos [...]

(citado en Cifuentes y Florián, 2004, p. 237). 
En noviembre de 1918 se fundó el dormitorio Emaús para mujeres y en agosto de 1919, el Asilo para niñas, todas estas obras, destinadas al barrio Las Cruces. Al cabo de una década con las obras en proceso de consolidación, recibieron la visita del arzobispo de Bogotá, Ismael Perdomo. La madre Margarita lo saludó con unos versos:

Hoy es el día tan deseado

Está de fiesta el Orfelinato

Llega a la casa nuestro Prelado

Y con nosotras estará un rato

(Carisma en canción y poesía, 1988, p. 113).

La visita del Arzobispo -a estas y otras instituciones- era una manera de estimular la acción que distintos sectores de la Iglesia realizaban entre los pobres y necesitados. Esta es una muestra de la manera como en estas primeras décadas del siglo, nacieron instituciones orientadas primordialmente a la asistencia.

\section{AproximACIÓN AL MUNDO DEL TRABAJO: LA JUVENTUD OBRERA CATÓLICA}

Con otra metodología pero con el mismo fin de re-cristianizar a la sociedad, el papa Pío XI consolidó la Acción Católica que venía perfilándose desde los pontificados de Pío X y Benedicto XV. Con este movimiento se oficializó un espacio para los laicos en las labores apostólicas de la jerarquía.

En Colombia se organizó la Acción Católica en 1933 y se aplicó la fórmula belga de Acción Católica diversificada (Cifuentes y Florián, 2004, p. 330). Sin embargo, desde la década de 1920 se fundaron en Bogotá organizaciones guiadas por los postulados del movimiento. La primera fue la Liga de Damas Católicas, conformada por mujeres de las élites y cuyo objetivo era defender la integración de la fe católica y la pureza de las costumbres. Luego se creó la Federación Nacional de Empleadas con el fin de aportar ayuda espiritual, recreativa y económica a las mujeres contratadas como secretarias, dependientas, enfermeras, traductoras, etc., que presionadas por la situación económica, tuvieron que trabajar en una época en la cual no era bien visto que las mujeres de ciertos sectores sociales salieran de su hogar a vincularse laboralmente en diferentes instituciones. Señoras de la alta sociedad, junto con el sacerdote Jorge Murcia, dirigían estas asociaciones (Cifuentes y Florián, 2004, p. 334). 


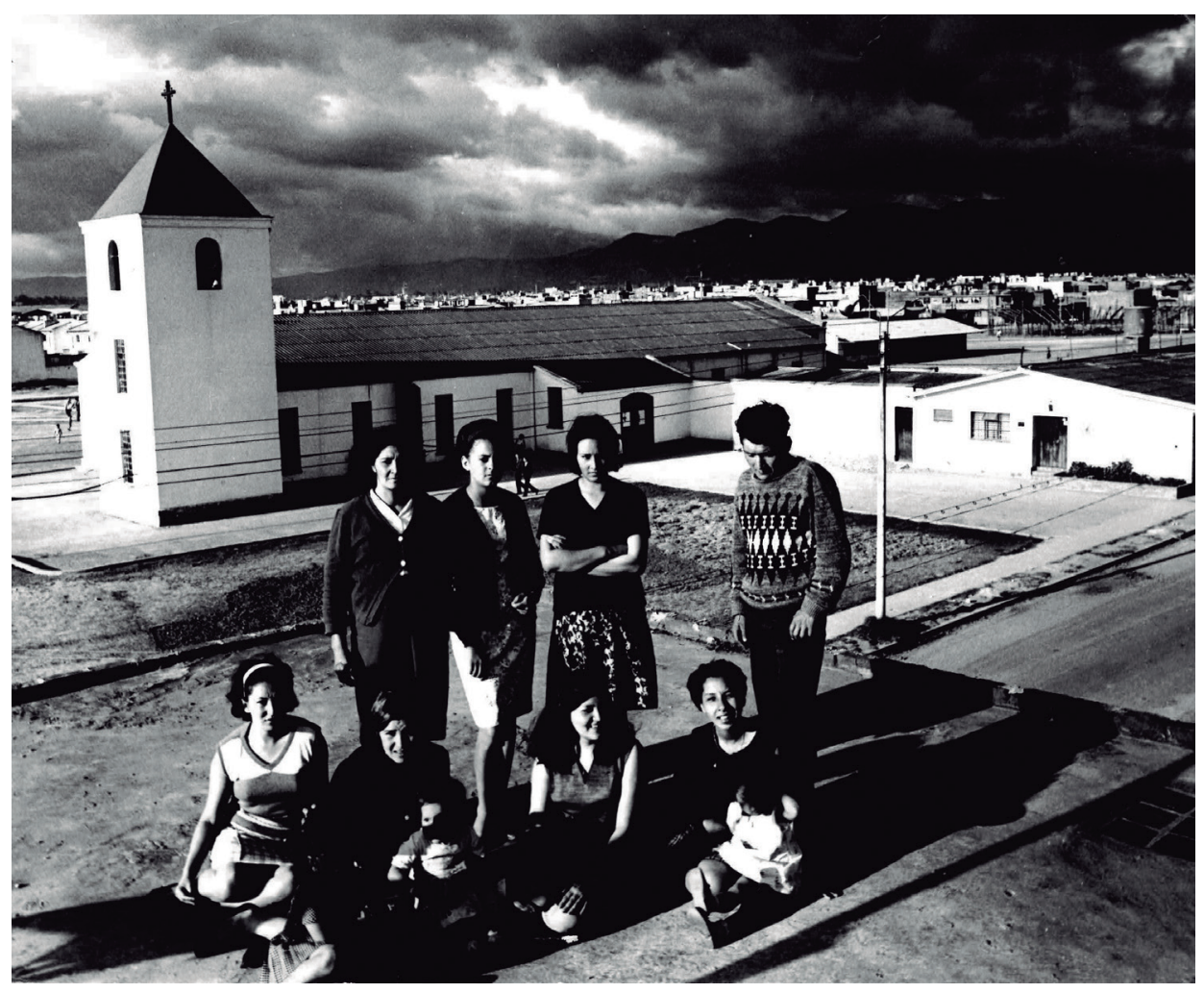

Figura 3. Juan Fonseca. (1975). Templo de Santa Cecilia en el sur de Bogotá. Una de las familias beneficiadas con la bendición del Pontífice que visitó Bogotá en 1968. Bogotá: Archivo de El Catolicismo. (Sin catalogar).

En diciembre de 1932, por iniciativa de los hermanos Jorge y Luis María Murcia Riaño, se fundó en Bogotá la Juventud Obrera Católica (JOC) siguiendo el modelo que los Murcia habían conocido en Bélgica, donde fue establecida por el padre José Cardijn. El objetivo del movimiento fue la "regeneración del mundo del trabajo". Las actividades desarrolladas por la JOC se inscribían en propuestas para conseguir la justicia social reclamando menos horas de trabajo, mejores sueldos y sitios de labor con condiciones de comodidad e higiene. Igualmente, reclamaban por los derechos de la mujer trabajadora y de manera particular, por un salario justo. Por otro lado, para los miembros de la Juventud Universitaria Católica que tenían influencia en la JOC, esta organización debía ser un instrumento para enfrentar al comunismo y al liberalismo (Cifuentes y Florián, 2004, p. 336). 
Las posiciones de la JOC de seguir denunciando las injusticias sociales y establecer distancia frente a las simpatías que sectores conservadores tenían por el fascismo y el corporativismo generó la animadversión, no solo del Partido Conservador sino del asesor nacional de la Acción Católica, el obispo Manuel González Arbeláez, muy cercano a Laureano Gómez.

El manejo personalista que González Arbeláez imprimía a las organizaciones que dirigía generó contradicciones con la JOC por sus posiciones, de alguna manera autónomas y profundizó las contradicciones con los hermanos Murcia a quienes acusaba de insubordinación frente a la jerarquía y del no sometimiento de la JOC a la Acción Católica. La tensión entre monseñor González Arbeláez, los hermanos Murcia y la JOC se resolvió a favor del Obispo, quien logró mediante intrigas que el Vaticano emitiera un concepto favorable para el desmantelamiento de la JOC (Cifuentes y Florián, 2004, p. 337). Pasados varios ańos, la JOC se vovió a recomponer, no sin encontrar serias dificultades, particularmente en los ańos sesenta y setenta.

\section{HACIA EL SINDICALISMO CATÓLICO}

Según Eugenio Colorado, antiguo miembro de la JOC, cuando esta se clausuró, los jóvenes activistas católicos quedaron a la deriva, sin orientación, pero ya tenían claro que debían seguir en la lucha por los derechos de los trabajadores. En estas condiciones, mantuvieron reuniones en las que, relata Colorado:

[...] nos pusimos a pensar: ¿qué hacer? [...] eramos zapateros, albañiles, mecánicos, sastres. [...] Encontramos una conexión con un estudiante de la Javeriana, Marino Recio, él tenía un grupo que se llamaba Unión Universitaria, eran un grupo de muchachos que querían trabajar por la gente y tenían en algunos barrios de Bogotá, centros para prestar servicio médico, de abogados, etc. [...] Ideamos círculos de estudio y encontramos que el organismo que más nos servía era el sindicalismo. Como ya teníamos contactos, yo era miembro de la Junta Directiva del sindicato de zapateros de Bogotá [...], el partido comunista dominaba el sindicato. Empecé a conocerlos y a admirar el trabajo de los comunistas (Entrevista personal, 1997 abril 29, Bogotá). 
Colorado dio una serie de ejemplos del trabajo de los comunistas: el compromiso, la mística y el interés por la situación de los trabajadores:

Eso nos hizo llegar a una serie de conclusiones. Tenemos que trabajar en el campo sindical, ¿para qué?, ¿contra el comunismo?: no. Para poder llevar los principios de la Iglesia que están en las encíclicas de León XIII, de Pío XI. Al estudiar este fenómeno encontramos que la doctrina social de la Iglesia era desconocida en los medios católicos. (Entrevista personal, 1997, abril 29, Bogotá).

Es evidente que en la actitud de Colorado y sus compañeros había un tanto de osadía al sustraerse del discurso y la actitud anticomunista que se manejaba entre el clero, los patronos, el partido conservador y buena parte del partido liberal.

Colorado narra el encuentro con el jesuita Vicente Andrade Valderrama y señala que se profundizaron las reflexiones sobre la situación de los obreros y el por qué los comunistas tenían éxito entre ellos. Llegaron a la conclusión que estos eran gente trabajadora, igual que los obreros católicos, con los mismos problemas y las mismas necesidades, solo que con los comunistas encontraban la posibilidad de luchar por la justicia social. Al respecto decía Colorado que sobre "el problema del comunismo" entendieron "que ellos estaban en una labor que tenía un fondo de justicia y que nosotros no podíamos ser enemigos acérrimos de ese planteamiento, sino ser mensajeros del mensaje de la Iglesia por la justicia social” (Entrevista personal, 1997, abril 29, Bogotá).

Colorado anotó que cuando llegaba el padre Andrade, ya tenían consolidado un grupo de obreros que formaban parte de la Unión Obrera, organización fundada por Colorado que luego tomaría el nombre de SETRAC (Selección de Trabajadores Católicos), una organización tan secreta que ni la familia de sus miembros podía saber de su existencia. A parte de una acentuada formación religiosa, hacían retiros anualmente, enfatizaban la formación sindical, trabajaban, estudiaban y se definían actividades de acuerdo con la situación del momento. Para formar parte de la SETRAC se tenían que cumplir una serie de requisitos: seis meses como aspirante y dos ańos para llegar a ser dirigente. Entre 1942 y 1943 la SETRAC cambió de nombre por CETRAC (Centro de Trabajadores Cristianos).

A finales de 1943, en una confrontación con los comunistas y los liberales -según palabras de Colorado- los dirigentes católicos fueron expulsados de los sindicatos. Los jesuitas que dirigían la Coordinación Nacional de Acción Social llamaron a estos trabajadores y los vincularon como funcionarios de dicha insti- 
tución. De esta manera y libres del compromiso laboral, se dedicaron de tiempo completo al trabajo con los obreros, no solo en Bogotá sino en todo el país.

Es interesante ver cómo el núcleo de antiguos dirigentes de la JOC de Bogotá se constituyó en un apoyo a dirigentes de otras partes del país que venían liderando sindicatos. Esto, sumado al fuerte apoyo de los jesuitas y del clero secular que siguiendo la orientación de la Conferencia Episcopal impulsaban el trabajo sindical, se constituyó en la oportunidad para la creación de una nueva central de trabajadores, la UTC (Unión de Trabajadores de Colombia) que contaba con el apoyo del partido conservador y de muchos patronos que anhelaban desembarazarse de las confrontaciones con la CTC (Confederación de Trabajadores de Colombia), una central influenciada por comunistas y liberales. La CTC pasaba en esos momentos por una crisis fruto de la división interna y de la represión del gobierno de Lleras Camargo que calificó el paro de Fedenal, (organización de los trabajadores del Río Magdalena) como subversivo, apreciación que coincidía con lo señalado por los sindicatos auspiciados por la Iglesia.

Los éxitos del sindicalismo católico son significativos durante la segunda mitad de la década de 1940 hasta la conformación del Frente Nacional. Sin demeritar la labor de los trabajadores católicos y del clero que los dirigía, hubo circunstancias políticas que los favorecieron y que se expresaron en el fortalecimiento de los gobiernos conservadores, incluido el de Rojas Pinilla, con la limitación de las libertades y la persecución a liberales y comunistas que prácticamente aniquiló la posibilidad de toda organización obrera diferente a la UTC.

Ante las críticas de los comunistas y liberales de carácter patronalista, confesional y conservador de la nueva confederación, un cofundador de la UTC, Justiniano Espinosa, refutó el hecho señalando que la UTC y la Fanal (Federación Agraria Nacional) fueron el resultado del trabajo de la CETRAC y de la Coordinadora de la Acción Social. La UTC se mantuvo bajo la influencia de la CETRAC y de los jesuitas hasta principios de los ańos setenta, cuando se retiraron Eugenio Colorado y el padre Vicente Andrade Valderrama por presiones internas (Cifuentes y Florián, 2004, pp. 342-355).

Al preguntarle a Colorado acerca de la dependencia de los sindicalistas católicos del clero, este señalaba que la hubo, pero que en el caso de Bogotá fue mucho menor que en Medellín, donde había paternalismo, tanto del clero como de los patronos que consideraban a los trabajadores poco capaces para darse una dirección autónoma. Colorado añadió que la cierta independencia que tuvieron los trabajadores de Bogotá se debió a la herencia de autonomía que quedó de la JOC (Entrevista personal, 1997, abril 29, Bogotá). Los co- 
mentarios de Colorado sobre la injerencia del clero y los patronos en Medellín se corrobora con los planteamientos de Alberto Mayor Mora en su libro Ética, trabajo y productividad en Antioquia, en el cual muestra los mecanismos que se idearon para ejercer tal control sobre los trabajadores; un control que trascendía el campo laboral y se introducía en la vida privada, particularmente de las obreras, con la creación de los Patronatos, una especie de internados en donde vivían las jóvenes trabajadoras que generalmente provenían del campo. La ayuda que se les prestaba tenía su costo en términos de autonomía, libertad, manejo del tiempo libre y espacios de socialización (Mayor, 1984).

En Bogotá el esfuerzo se centró en la formación de líderes que pudieran incidir en los sindicatos y en otras organizaciones a las que dieron vida, como la fundación de cooperativas en las que CETRAC tuvo un gran impacto.

\section{NUEVOS ACONTECIMIENTOS Y NUEVOS RETOS}

Los dramáticos acontecimientos del 9 de abril de 1948 y la ola de violencia desbordada generaron entre muchos -particularmente en la Iglesia- preguntas y reflexiones acerca de las causas de los trágicos hechos. En la Arquidiócesis de Bogotá se desarrollaron ciertas acciones que anunciaban vientos renovadores. A mediados de la década de 1950 el cardenal Crisanto Luque envió sacerdotes a estudiar sociología a Lovaina, entre ellos Camilo Torres y Gustavo Pérez, y creó un centro de investigaciones socio-religiosas. Además de fortalecer la acción pastoral en el sur de la ciudad, se crearon equipos de trabajo entre el clero, como por ejemplo, la Unión Parroquial del Sur (Cifuentes y Florián, 2004, p. 357).

Por otra parte, surgieron instituciones -ya no de carácter asistencial sino formativo- particularmente entre los jóvenes. El sacerdote Luis María Fernández de la Arquidiócesis de Bogotá, concluyó que si se hubiera trabajado a fondo con la juventud esta situación, la violencia y los desmanes producidos como reacción al 9 de abril, no se habrían presentado. Es así como en respuesta a sus inquietudes, el 3 de septiembre de 1953 se fundó la Central de Juventudes, "con el objetivo de contribuir a la formación integral de líderes juveniles con fe auténtica para alcanzar su madurez humana y cristiana" ( $E l$ Catolicismo, 2013, septiembre 8-21, p. 13).

A los pocos años, en 1956 -con gran imaginación- la Central fue dando forma, no solo a diversas actividades sino moldeando organizaciones como Colonias de vacaciones, el Centro Deportivo Obrero, Casas de la Juventud y la Central de Juventudes Trabajadoras. Estas obras buscaban responder a los 


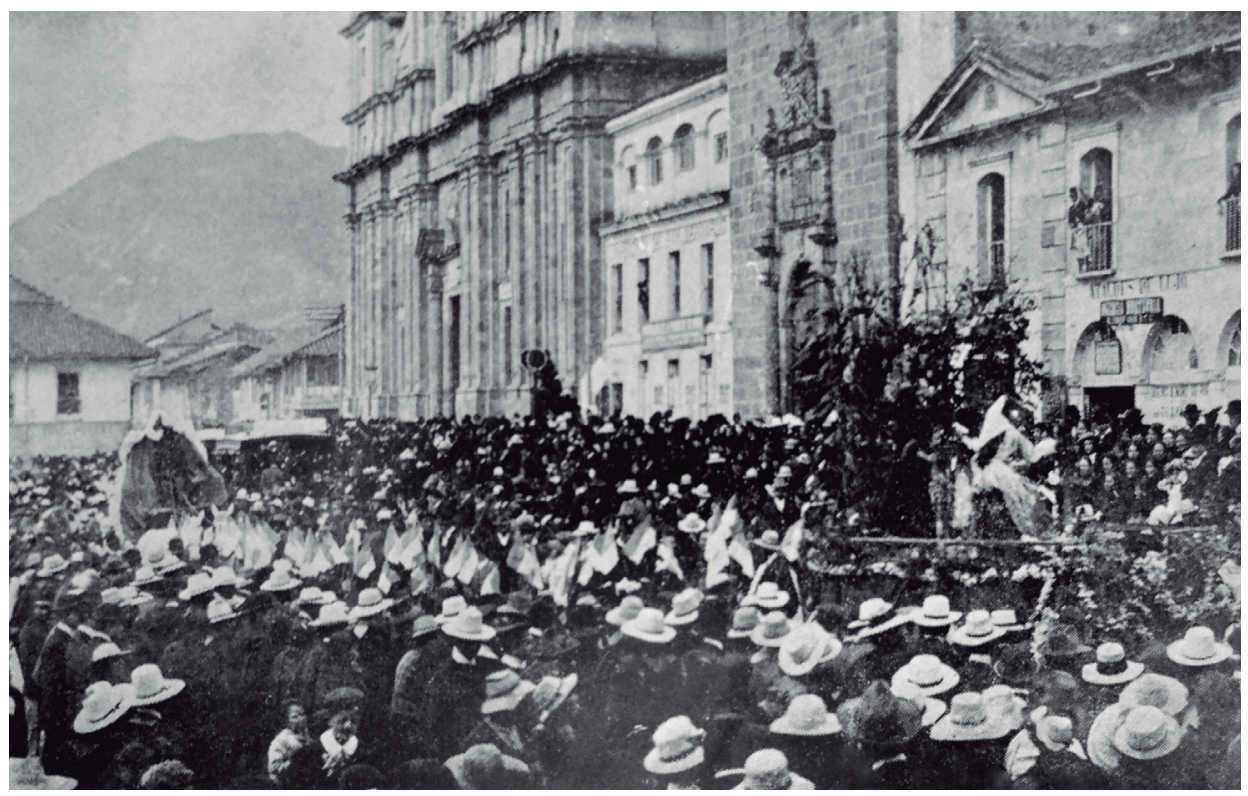

Figura 4. Anónimo. (1914). Procesión del Círculo de Obreros. En: Primer Congreso Eucarístico Nacional de Colombia. Bogotá, septiembre de 1913. Bogotá: Escuela Tipográfica Salesiana p. 111.

cambios que se iban presentando en el país paulatinamente y que apuntaban a una mayor concentración de la población en las ciudades, particularmente en Bogotá. Unido a lo anterior y ya al iniciar la década de 1960, se presentó una mayor cobertura en educación secundaria y universitaria, lo que multiplicó la presencia de los jóvenes en la ciudad. Hacia 1960 la Central de Juventudes se reestructuró, adicionalmente instituyó servicios para atender a los jóvenes en aspectos sociales, culturales, deportivos y de recreación dirigida. En 1961 se fundó la Escuela de líderes; en 1963 emergió una modalidad novedosa para vincular a jóvenes voluntarios a un trabajo como Misioneros Juveniles y en 1967 los cursos de Pastoral Juvenil, organizaciones que aún mantienen su actividad atrayendo a jóvenes campesinos, estudiantes, obreros y profesionales. Las actividades de la Central de Juventudes se han extendido a todo el país y los misioneros juveniles han prestado su servicio a diversas diócesis.

En los años sesenta el país asistió a un rápido proceso de urbanización, al crecimiento de las clases medias, a la vinculación de la mujer al trabajo y por supuesto, toda la sociedad se vio permeada por la apertura cultural, hechos que posibilitaron expresiones de secularismo. La Iglesia también recibió el impacto de tal situación que afectó el campo religioso. Eran los tiempos del 
Concilio Vaticano II y posteriormente la Conferencia del CELAM de Medellín, previos a la aparición de Golconda y la presencia del sacerdote Camilo Torres, que significó un cuestionamiento fuerte a la vivencia religiosa y sobre todo a las relaciones entre el Estado, la Iglesia y la sociedad.

Teniendo en cuenta el marco anterior, se entiende la orientación que se daba en la formación de los líderes juveniles de la Central de Juventudes. Tal vez había un afán de sustraer a los jóvenes de las influencias de las diferentes corrientes ideológicas, manteniendo esquemas usados por la Iglesia y sus instituciones en épocas anteriores. En una entrevista realizada en 1997 a un antiguo Misionero Juvenil, posteriormente un académico de prestigio, sobre su experiencia durante el tiempo que estuvo vinculado al movimiento, señalaba:

Cuando yo llego a la Central al curso de líderes me encuentro que es dirigida por el padre Fernández y alrededor de él había un grupo de gente de cierto nivel [...] a uno le estaban vendiendo un discurso católico anticomunista [...] uno de los conferencistas principales de la escuela era Carlos Corsi Otálora, actual senador por el movimiento Laicos por Colombia, José Galat, y un filósofo de la Nacional Fernando Urbina. [...] había un mensaje cristiano, filosófico, teológico, sociológico, y mucha dinámica de grupo, mucha actividad recreativa [...] Al terminar la escuela nos hacen una propuesta y es que nos vinculemos como misioneros laicos [...] indudablemente que los mecanismos eran bastante halagüeños, venirse para Bogotá, irse a otro lugar [...] Yo fui uno de los que se ofreció. Me voy a mi pueblo, termino mi bachillerato y regreso a la segunda escuela [...] había un libro que se llamaba $E l$ Manifiesto de la Juventud Colombiana, que después entendí que era como la contrarréplica al Manifiesto Comunista. Trabajé como misionero dos años en el sur del Tolima y en el Huila [...] Entre todas las cosas que suceden allí, sacamos una conclusión de que lo que estábamos haciendo, que por ahí no era, hablar de amor, de paz, en donde predominaba la agresión, el desafecto, la violencia, la pobreza, el atraso. Era el año 1969, regresamos a Bogotá, nos ofrecen oportunidades, estudiar filosofía o ciencias religiosas en la Santo Tomás o en la Javeriana. [...] Nos daban alojamiento y seguíamos haciendo labores, con un régimen disciplinario con el que pretendían aislarnos, un ejemplo que hoy parece chistoso, un muchacho trajo Cien Años de Soledad y nosotros la leímos, eso no 
era bien visto, no era el tipo de lecturas que debíamos hacer. [...] En medio de la problemática social y política que se vivía en el momento, hay contactos con estudiantes de otras universidades, de la Nacional, vienen las discusiones [...] decido retirarme y me voy a estudiar de noche y a buscar cómo ganarme la vida (Entrevista personal, 1997, noviembre 6).

Hoy la Central de Juventudes cumple sesenta años con gran dinamismo y fiel a los objetivos trazados por el padre Fernández.

\section{SOBRE LA PASTORAL SOCIAL EN 1970}

Las conclusiones del Concilio Vaticano II y de la Conferencia del CELAM en Medellín no siempre fueron, sino entendidas, por lo menos asumidas por la jerarquía en Colombia como se esperaba, y de esa situación no escapaba la Arquidiócesis de Bogotá. En relación con el Concilio, la jerarquía colombiana no estaba preparada para asimilar las propuestas de apertura y de diálogo con el mundo moderno en el marco de respeto a las libertades, entre ellas a la libertad religiosa (Restrepo, 1995; González, 1997).

Las contradicciones no se hicieron esperar entre sectores del clero que pretendían reformas urgentes y la mayoría de la jerarquía anclada en la tradición y poco acostumbrada al cuestionamiento de su acción. En el caso de Bogotá, los disensos llevaron a la clausura por parte del cardenal Luis Concha Córdoba del periódico El Catolicismo, y

[sus] directores (uno de ellos, el después primado colombiano monseñor Mario Revollo Bravo) se vieron obligados a renunciar. El cardenal estaba en desacuerdo con la orientación del periódico, que se había dedicado a difundir los temas conciliares y había planteado la necesidad de una 'vasta reforma de estructuras'. Por esto, 95 sacerdotes pidieron al cardenal una orientación concreta sobre la aplicación de los documentos conciliares. El prelado respondió que las enseñanzas del Vaticano II sólo obligaban a la Iglesia colombiana a cambios litúrgicos y no a cambios sociales (González, 1997, p. 50).

Sumado a lo anterior, la jerarquía colombiana pero en particular la Arquidiócesis de Bogotá, venía de enfrentar lo sucedido con el padre Cami- 
lo Torres -no precisamente con acierto- luego de que este emprendiera la acción pastoral para aproximarse a los graves problemas que atravesaba el país y que lo condujeron a elegir una salida diferente a la que era usual en la Iglesia colombiana, optando al final por la ruptura definitiva y la guerrilla al verse presionado por múltiples factores.

Esta situación tuvo repercusiones en muchos ámbitos, entre ellos el cuestionamiento a la manera como la Arquidiócesis se acercaba a la realidad de la ciudad que condensaba toda la problemática social que se vivía en el país. El documento de trabajo La Pastoral Social en la Arquidiócesis de Bogotá, de junio de 1970, presentado por el Departamento de Pastoral, deja ver los interrogantes en torno al tema y propone hacer una reflexión sobre la presencia de la Iglesia local en lo social.

El enunciado es fuerte al señalar el siguiente diagnóstico: "Existe en la Arquidiócesis de Bogotá, prácticamente en todos los sectores, una inquietud que denuncia la ausencia de una acción pastoral social". Aunque consideran que no pueden aceptar el juicio tan negativo, no rehúsan examinar la situación. Parten de señalar algunas causas: deficiencias en lo que se hace, una concepción subjetiva de la pastoral social con marcada tendencia hacia lo meramente temporal; el desconocimiento de lo que se está ejecutando y una visión parcializada de la pastoral social, induciendo a pensar que lo desarrollado no es lo apropiado para adelantar el compromiso de la Arquidiócesis en el orden temporal. El documento pasa a hacer un análisis de la "realidad de la pastoral social arquidiocesana" y hace un recuento de las actividades dividiéndolas en obras de formación, promoción, asesoría, acción directa, beneficencia y acción de grupos. Evalúa asimismo la labor del clero, los laicos y las religiosas; afirma que el clero ha pasado por diversas etapas y las caracteriza así:

1944-1960: Despertar de estos problemas y estudio en particular de la acción de grupos; 1960-1965: Asistencialismo y un esfuerzo de cambio hacia la acción social muy imprecisa; 19651967: Crisis; 1967-1970: Esfuerzos de rehabilitación y nueva revisión y reflexión; 1970: Orientaciones hacia la acción y el diálogo.

Sobre los Laicos: Acción cristiana y acción política, asistencialismo, acción social y crisis de cambio. Las Religiosas: Educación tradicional, asistencialismo, esfuerzo de revisión y crisis de cambio (ACCPC, s.f., pp. 3-4). 
Unido a lo anterior señala que se evidencia cierta marginación del clero y de muchos fieles del apostolado social. Dice que la acción ha evolucionado hacia la promoción humana, sin embargo que se utiliza este apostolado como una especie de "anzuelo y de proselitismo"; resalta el activismo en la parte asistencial con un marcado acento paternalista y clerical.

Al caracterizar la tendencia hacia lo temporal, señala actitudes más políticas que pastorales como el caso del Movimiento Golconda y la Teología de la Liberación. En este campo señala aspectos positivos como un avance en la reflexión teológica en el análisis de la realidad, la construcción del ser humano y la sociedad con un contenido de liberación, aunque sobre éste se dice que privilegia el contenido sociológico.

Entre los aspectos negativos afirma que se parte de apreciaciones simplistas en el análisis y en las soluciones. Que se contrapone liberación a desarrollo, se pierde el sentido del pecado personal y que hay cierta tendencia a reducir la conciencia de pecado al pecado de las estructuras, en particular a la injusticia social y la liberación no presenta una dimensión universal, da impresión que lo que se busca es la condenación de unos para alcanzar la liberación de otros (ACCPC, s.f., pp. 6-8).

El documento también indica la falta de testimonio determinado por comportamientos eclesiales que dan la impresión de una Iglesia privilegiada y que esto afecta el contenido de la pastoral social. Subraya que no existe un verdadero estudio de la realidad social y que la planeación está ausente, al igual que no hay claridad en los criterios de promoción humana.

Para contrarrestar lo señalado propone unas "líneas de acción" que se pueden resumir en los siguientes puntos: la pastoral social debe estar siempre atenta a los hechos humanos que se van sucediendo, interpretándolos a la luz de la fe; el compromiso de toda la Arquidiócesis con personas y grupos más necesitados, la integración de los actores que la ejecutan, el cumplimiento de deberes cívico sociales; plantea reivindicar derechos pero también ser conscientes de los deberes; ser ejemplo de unidad y fraternidad y poner particular atención a las comunidades eclesiales de base.

Propone que las distintas instituciones revisen las obras y si es necesario, que renuncien a aquellas que no tengan sentido para dar paso a quienes tienen capacidad de dirigir obras temporales. Además indica la necesidad de una mayor comunicación de bienes, de fortalecer el diálogo en todos los niveles de la comunidad arquidiocesana y tener claro que el gran compromiso de la presencia de la Iglesia en el mundo es el complemento de la tarea evangelizadora. Apunta que la labor pastoral social debe ocuparse de la liberación del hom- 
bre de manera integral y universal. Para finalizar, señala acciones concretas a sacerdotes, religiosos y laicos, resaltando que el influjo de los primeros en el cambio religioso y social es el testimonio de los religiosos en el trabajo con las personas, el de "hacerlos vivir su dignidad humana y el de servirles en orden a los bienes de la Redención". A los laicos les sugiere el fortalecimiento de la familia, que esta sea promotora del desarrollo y a los jóvenes los insta a incidir en el cambio social del país (ACCPC, s.f., pp 18-22).

Entre las acciones, el texto llama a la construcción de la comunidad, de "comunidades de vida", comunidades eclesiales, a ser testimonio de vida comunitaria, a la formación integral del hombre, a la formación de la conciencia social y a la coordinación de esfuerzos y de instituciones. Sin duda que el documento muestra un nivel de autocrítica y un deseo de buscar nuevos rumbos y metodologías en las tareas de la Acción social, en momentos en que la crisis interna de la Iglesia colombiana también afecta y de manera muy fuerte a la Arquidiócesis de Bogotá.

\section{DINAMIZACIÓN DE LA PRESENCIA EN LAS NUEVAS COYUNTURAS}

Al finalizar 1972 aparece un manifiesto del grupo SAL, Sacerdotes para América Latina, que en una actitud beligerante denuncia "situaciones concretas de los poderes eclesiásticos y civiles". El grupo SAL es expresión del radicalismo con que muchos sacerdotes, religiosos y laicos asumieron su postura política. Las confrontaciones con la jerarquía y estos grupos, llevó a endurecer posiciones que se reflejaban en las condenas que en 1976 y luego en 1982, hizo la Conferencia Episcopal a organizaciones como el Cinep, Iplaj y revistas como Denuncia, Solidaridad y Controversia (González, 1991).

Entre tanto el conflicto social y armado se agudizaba en el país con efectos gravísimos en términos de violación de derechos humanos donde estaban comprometidos, no solo lo grupos armados ilegales sino sectores de los organismos del Estado, a través de torturas, asesinatos selectivos, desapariciones y desplazamiento, particularmente de activistas sindicales, estudiantiles y miembros de organizaciones de izquierda. En estas circunstancias es notoria la acción de muchos miembros del clero desde obispos, sacerdotes, religiosos y algunos laicos que se vinculan a la defensa de los derechos humanos y al acompañamiento de las víctimas.

El interés de la Arquidiócesis por hacer una presencia más efectiva la llevó a vincularse en estudios sobre el desplazamiento, a promover y participar en 
foros sobre migraciones y sustentar programas de ayuda utilizando la información de entidades estatales y privadas sobre diversas problemáticas. De esta manera orienta de forma más efectiva el trabajo, como el acompañamiento y apoyo a desplazados y migrantes a través de instituciones como la Fundación de Atención al Migrante creada en el 2002, la cual fortalece la acción que se venía generando desde finales los años ochenta.

La Fundación Banco Arquidiocesano de Alimentos-creado en el 2001-buscó por su parte articular esfuerzos de la empresa privada y organizaciones sin ánimo de lucro para ayudar a la población vulnerable que sufre necesidades en materia de seguridad alimentaria. Igualmente el Programa de Redes de la Fundación San Antonio, ofrece nivelación de niños desescolarizados en la utilización del tiempo libre, complementando su rutina diaria con actividades artísticas, deportivas y de prevención psicosocial. En la pastoral penitenciaria ofrece programas de protección de adolescentes e infantes hijos de la población carcelaria, apoyo espiritual y de capacitación a las familias de los penados (El Catolicismo, 2013, septiembre 8-15).

Los ejemplos anteriores y las múltiples instituciones atendidas por religiosos y laicos en toda la Arquidiócesis, son expresión de una presencia más solícita con nuevas metodologías y criterios que permiten visualizar la presencia de los católicos en medio de la población más vulnerable. Entre otras cosas, porque el fenómeno de crecimiento urbano que desbordó a la ciudad durante la segunda mitad del siglo XX, impactaba la vida de los habitantes más pobres de la ciudad. Así por ejemplo, en 1950 la tasa de crecimiento había rondado $5 \%$, entre 1951 y 1964 alcanzó a 6,9 \% y 6 \% entre 1964 y 1973 (Gouëset, 1998), de lejos las más altas por encima del ritmo de crecimiento de cualquier otro centro urbano del país. Como había ocurrido en décadas anteriores, la capacidad de respuesta del Estado en la atención a los cientos de miles de víctimas de la violencia seguía siendo muy modesta y en ocasiones inexistente.

Pero un fenómeno complejo se convirtió en crítico, pues en las dos últimas décadas del siglo XX los migrantes llegaron a la ciudad empujados por el miedo, desalojados a la fuerza indistintamente por actores del conflicto armado que buscaban consolidar su poder territorial a sangre y fuego, condenando a miles de personas a llegar a la ciudad sin más posesiones que lo que llevasen encima. En efecto, el desplazamiento por causas relacionadas con el conflicto armado interno determinaron que solo en el año 2000 llegaran a Bogotá en condición de desplazamiento por la violencia "un promedio de 3.580 personas por mes, 119 al día [es decir] cinco personas por hora” (Arquidiócesis de Bogotá - Codhes, 2001, p. 15). Bogotá se convertía, según este mismo estudio, en el principal refugio de los colombianos que huían de la guerra. 


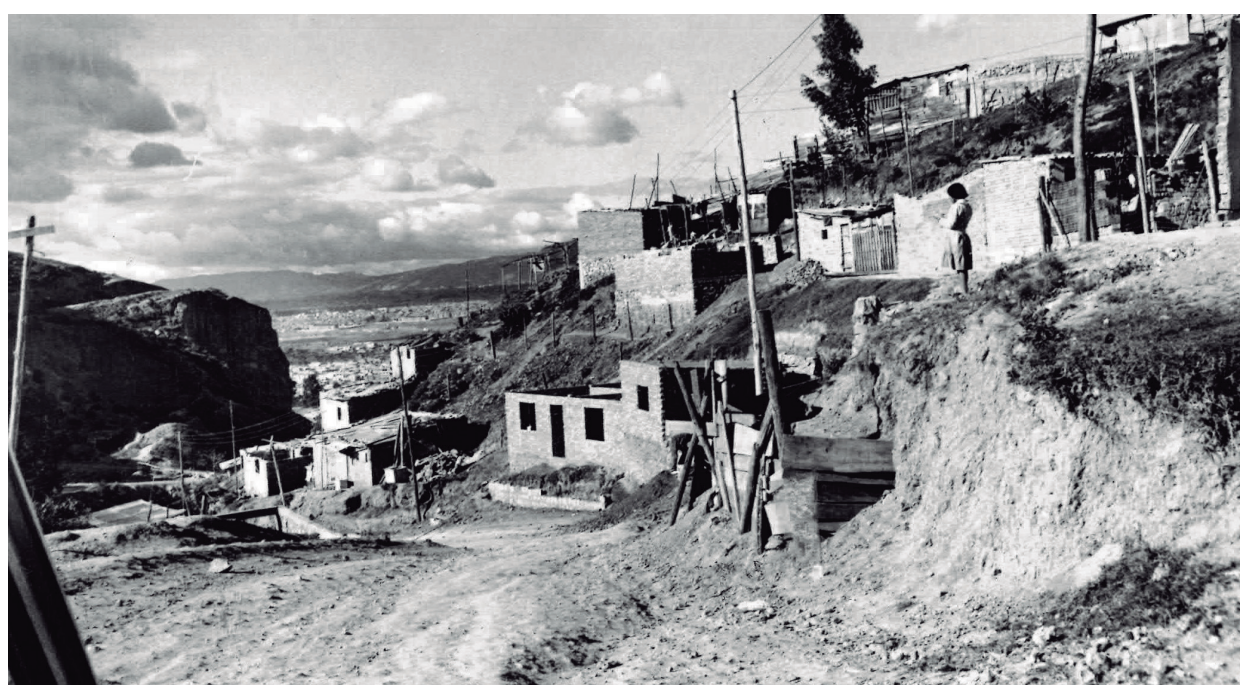

Figura 5. Anónimo. (1987). Villa Esmeralda. Bogotá: Archivo de El Catolicismo. (Sin catalogar).

Es de hecho sintomática la presencia cada vez más protagónica y el papel también paulatinamente más activo de la Comisión Pastoral de Movilidad Humana y del ya mencionado Centro de Atención al Migrante, pues el fenómeno del desplazamiento, dadas sus connotaciones de crisis social, había captado la atención de la Conferencia Episcopal Colombiana desde varios ańos antes. Gracias a estudios pioneros en el tema del desplazamiento, se determinó que entre 1985 y 2001 llegaron a la capital del país 403.668 desplazados, lo que correspondía al 6,7 \% de la población total de la ciudad y al 18,6 \% del total de personas desplazadas en el país (Arquidiócesis de Bogotá - Codhes, 2001).

Esta preocupación se estructuraba en dos vías, por un lado en consonancia con los objetivos pastorales de la Iglesia en el marco de "la espiritualidad del Buen Samaritano para hacer efectiva la práctica misericordiosa de la Iglesia Arquidiocesana de Bogotá" (Arquidiócesis de Bogotá - Codhes, 2001); pero por otro lado, miembros de la Iglesia católica fueron objeto de violencia armada selectiva en el periodo de intensificación y radicalización de la violencia a finales de la década de 1990. En los diez años que corren entre 1995 y 2005, 44 religiosos fueron asesinados, 29 secuestrados, 40 amenazados y 12 heridos o agredidos (Clavijo, 2005, p. 6), en otras palabras, la institución religiosa se convertía también en una víctima del conflicto armado. Desde ese punto de vista no resulta extrańo que existiera un interés creciente por los pobladores que arribaban a Bogotá en condición de víctimas directas de los rigores de las acciones armadas acaecidas en casi todo el país. 


\section{CONSIDERACIONES FINALES}

A lo largo del siglo XX la Iglesia católica fue un actor principal y determinante en el acontecer político y social del país. En su condición de institución rectora del devenir espiritual de millones de fieles, su rol estaba destinado a ser protagónico, aun cuando el proceso de secularización se fuera radicalizando conforme avanzaba el siglo. Con frecuencia, su actuación fue decisiva entre otras cosas por su influencia en el devenir de los asuntos del Estado, por una agenda política propia y por su influencia sobre la masa de fieles. Esta suerte de intereses determinaron la importancia en la definición de la cuestión social, que a lo largo del siglo XX estuvo profundamente influenciada por diferentes enfoques.

Se puede seguir la pista a un objetivo central de comienzos del siglo XX, en la que hubo una abierta y frontal lucha en contra de lo que se presentía como un avance vigoroso de las ideas comunistas y socialistas, ofreciéndose a través de diversos programas el acompañamiento a las clases trabajadoras, presentadas entonces como las más expuestas a este tipo de "influjos"; estrategias que por momentos mostraban una especie de "encerramiento de los beneficiados" bajo un discurso moralista y ciertamente maniqueo.

Aunque hubo un accionar extendido en la cuestión social, es decir, en los problemas que afectaban al entorno humano de miles de personas pobres $\mathrm{y}$ de asalariados, la intervención pocas veces cuestionó las causas objetivas de los problemas sociales. No obstante, algunos cambios fueron configurándose, pues una serie de procesos económicos, políticos y sociales presionaron el acercamiento al análisis de condiciones estructurales de pobreza e inequidad en amplios sectores de la población, promoviendo una "cierta apertura" ideológica, pero sobre todo fomentando la ayuda sin una necesaria imposición del credo a los beneficiados. De ese modo y ciertamente por una aproximación y un trabajo pastoral continuo con los más débiles en sectores pobres y en medio de poblaciones desamparadas, cuando el crecimiento de las periferias urbanas estuvo profundamente influenciado por el conflicto armado, hubo la necesidad de fortalecer las organizaciones que buscaban hacer acompañamiento y paliar los efectos del conflicto.

Esta continua preocupación, el acompañamiento constante y el interés sostenido en la cuestión social establecieron un papel altamente relevante de la Arquidiócesis en la construcción de la ciudad y en la organización social de muchos sectores de pobres urbanos luego convertidos en víctimas. Si esta pre- 
sencia contribuyó a mejorar el estado de estas poblaciones, si fue desinteresada o si ha sido consecuente en el tiempo o se ha movido al vaivén de intereses políticos aún está por determinarse, pero su alcance se presiente de largo aliento y de protagonismo innegable.

\section{REFERENCIAS}

Archila, M. (1991). Cultura e identidad obrera. Colombia 1910 - 1945. Bogotá: Cinep.

Archivo Capitular de la Catedral Primada de Colombia (ACCPC). (s.f.). La Pastoral Social en la Arquidiócesis de Bogotá. Sin catalogar.

Arquidiócesis de Bogotá - Codhes (2001). Senderos: rostros invisibles del desplazamiento en Bogotá. Bogotá: Kimpress.

Calvo, O. y Saade, M. (2002). La ciudad en cuarentena. Chicha, patología social y profilaxis. Bogotá: Ministerio de Cultura.

Cifuentes, M. y Florián, A. (2004). El catolicismo social: entre el integralismo y la teología de la liberación (pp. 321-372). En A, Bidegain. Historia del Cristianismo en Colombia. Bogotá: Taurus.

Clavijo, B. (2005). La Iglesia. Victima constante del conflicto armado en Colombia. Bogotá: Ed. Federación de Organizaciones No Gubernamentales - Verdad Colombia.

Colón, L. (2013). Medicina, ingeniería y urbanismo. El papel de las ideas higienistas en los cambios de Bogotá en la primera mitad del siglo XX. (Texto inédito). Conferencias Episcopales de Colombia. Tomo I. 1908 - 1953. (s.f.). Bogotá: Ediciones El Catolicismo.

Cortés, F. (2007). Llega el mutualismo a Colombia. Disponible en: http:// lideremprendedor.blogspot.com

Del Buen Pastor, M. (s. f.). Margarita Fonseca Silvestre. Hizo de su vida un servicio. Bogotá: Siervas de Cristo Sacerdote.

El Catolicismo (2013, septiembre 8 - 15). Bogotá.

El Catolicismo (2013, septiembre 8 -21). Central de Juventudes: 60 años construyendo un mundo mejor, 13.

González, F. (1991). La Iglesia Jerárquica: actor ausente. En F, Leal y L, Zamosc, L. (Comps.) Al filo del caos. Crisis política en la Colombia de los años 80. Bogotá: Tercer Mundo Editores.

González, F. (1997). Poderes enfrentados. Iglesia y Estado en Colombia. Bogotá: Cinep. 
Gouëset, V. (1998). Bogotá: nacimiento de una metrópoli. La originalidad del proceso de concentración urbana en Colombia en el siglo XX. Bogotá: Tercer Mundo editores.

Hall, P. (1996). Ciudades del mañana. Historia del urbanismo en el siglo XX. Barcelona: Ediciones del Serbal.

Hernández, R. (2010). La urbanización San Francisco Javier. Retoño del circulo de obreros (en su centenario). Esempi di architettura on-line. Disponible en: http://www.esempidiarchitettura.it/articoli.php?mod=oggetti\&o_nome $=$ articolo $\& \bmod A z i o n e=s c h e d a \& o \_i d=145 \_I T A$

Kalmanovitz, S. (Ed.). (2010). Nueva historia económica de Colombia. Bogotá: Taurus - Universidad Jorge Tadeo Lozano.

La Iglesia (1910, noviembre 25). 5 (21-22), 668-691.

La Iglesia. (1915, Marzo 15). X (5).

La Iglesia (1916, marzo 15). 10 (1-24), 109-118.

La Iglesia (1917, mayo 1). 10 (1-24), 65.

La Iglesia (1919, diciembre 15). 14 (1-24), 25 - 26.

La Iglesia (1920, marzo 15). 15 (1-24).

León XIII. (1891). Encíclica Rerum Novarum. Disponible en http://www. oocities.org/ar/magisterio_iglesia/leon_13/rerum_novarum_1.html

Mayor, A. (1984). Ética, trabajo y productividad en Antioquia. Bogotá: Tercer Mundo Editores.

Mejía, G. (2002). Los años del cambio: historia urbana de Bogotá 1820 1910. Bogotá: CEJA.

Restrepo, J. (1995). La revolución de las sotanas. Bogotá: Planeta.

Saldarriaga, A. (1994). Villa Javier: un experimento en vivienda social en Bogotá. En Londoño, R. y Saldarriaga, A. La ciudad de Dios en Bogotá. Barrio Villa Javier (pp. 71-125). Bogotá: Fundación Social.

Siervas de Cristo Sacerdote. (1988). Carisma en canción y poesía. Bogotá: Talleres de Graciela Impresores.

Vargas, J. y Zambrano, F. (1988). Santa Fe y Bogotá: Evolución histórica y servicios públicos (1600 - 1957). En Bogotá 450 años: retos y realidades (pp. 11-92). Bogotá, Foro - IFEA.

Vélez, A. y Montoya, J. (2001). Mutualismo Paso a Paso. Opción para el desarrollo popular. Bogotá: Ed. Centro de Investigaciones Sociales. Disponible en: www.mutualcompartir.org/Compartir/Historiamutualismo.pdf

Zambrano, F. (2007). Historia de Bogotá. Tomo III. Bogotá: Villegas Editores. 


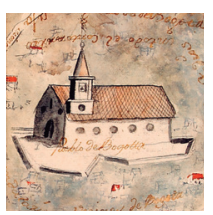




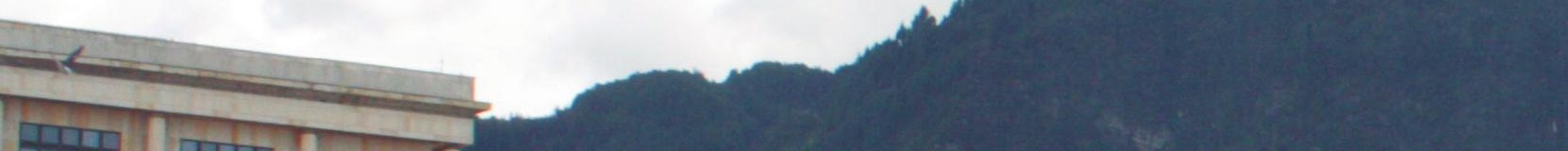

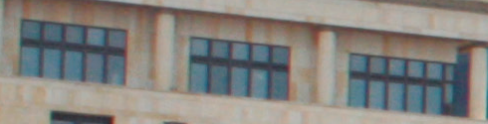

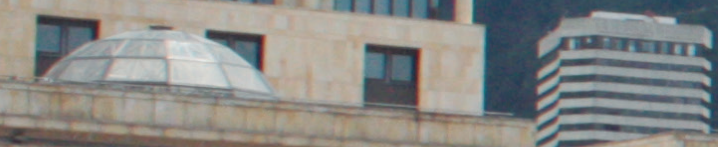

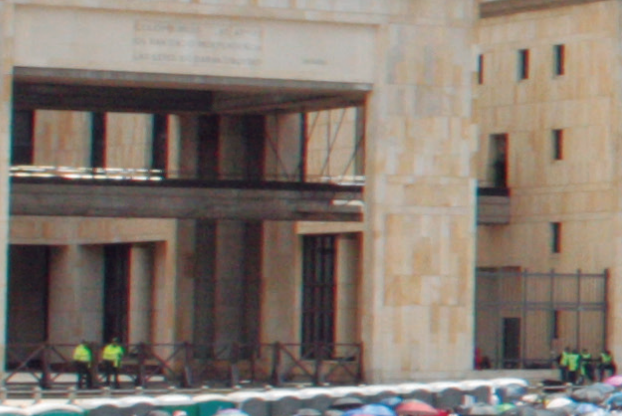

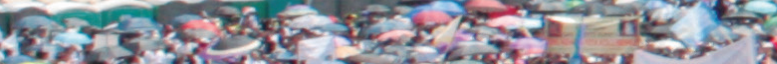

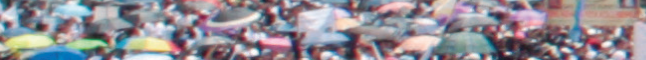

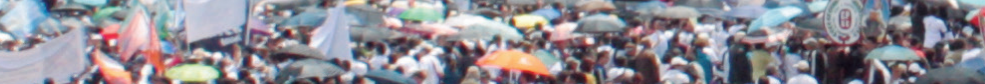

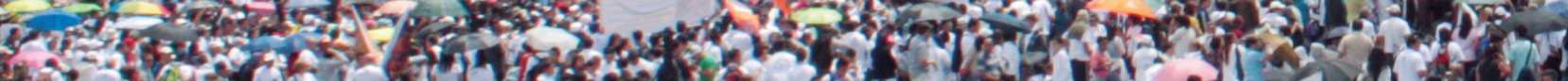

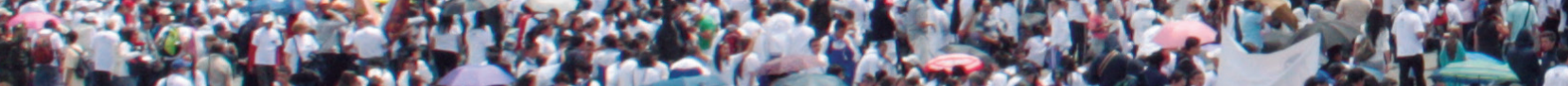

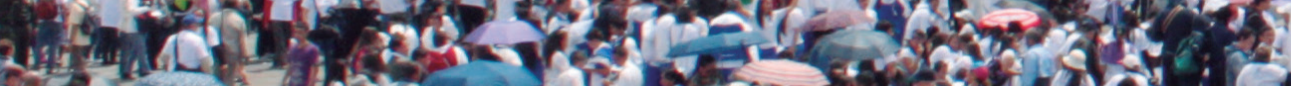

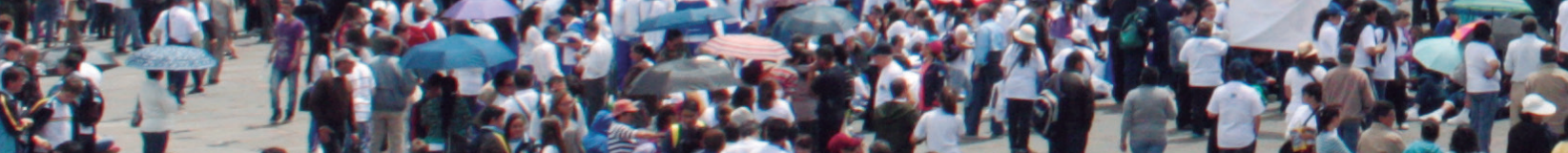

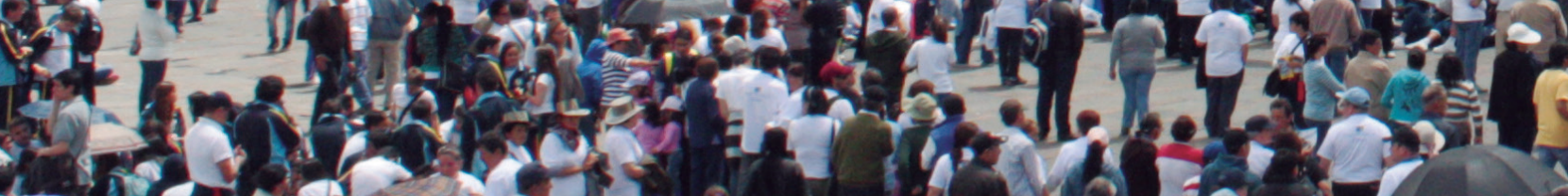

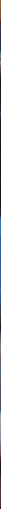




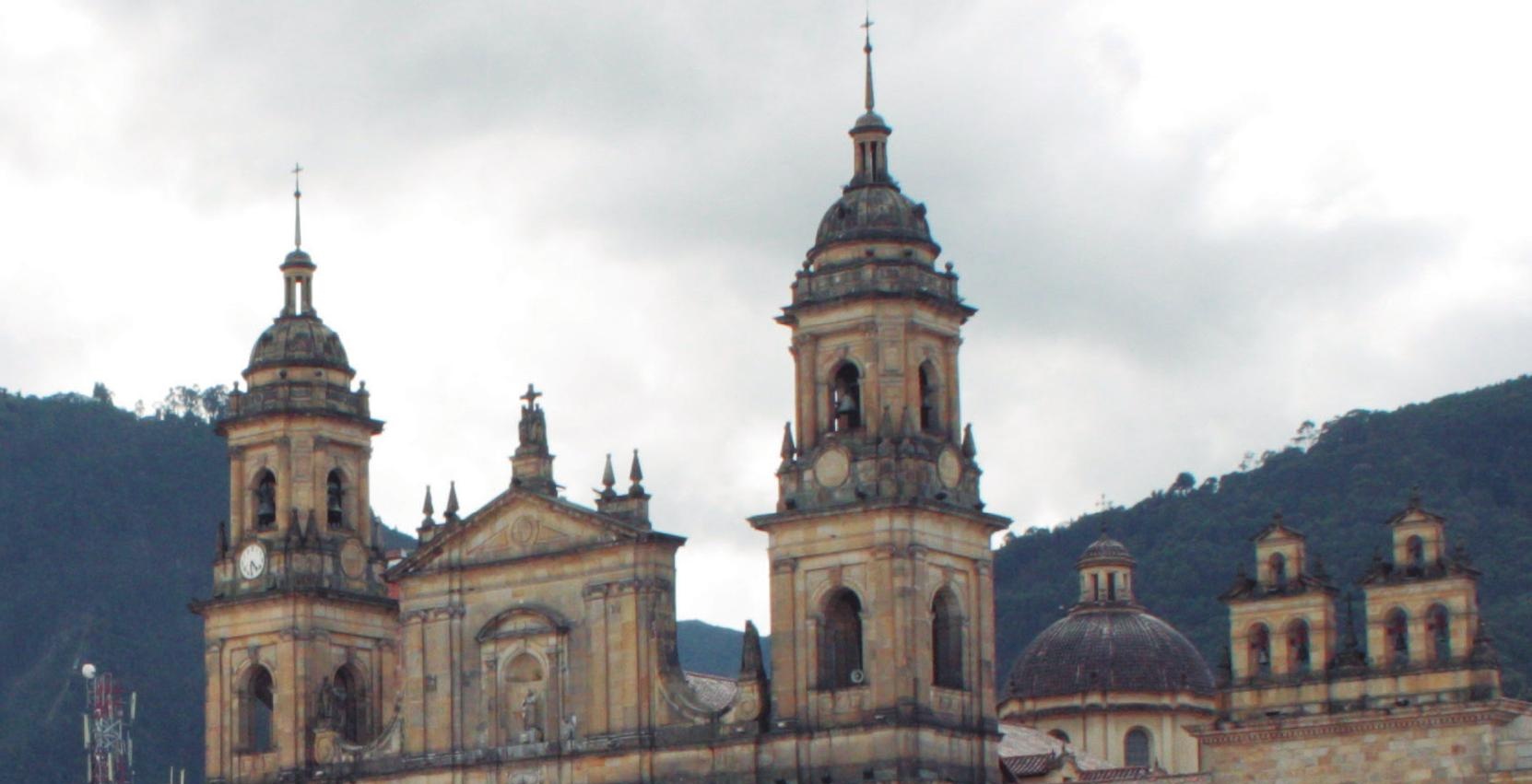

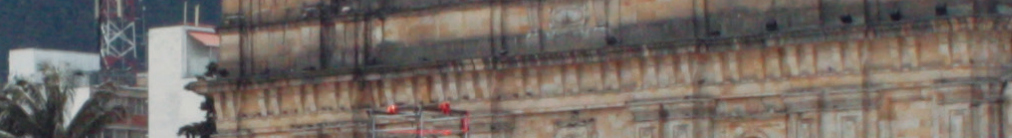

4.

IIi.

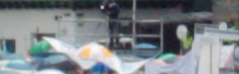

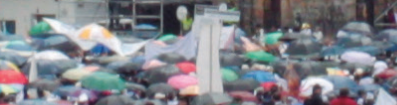

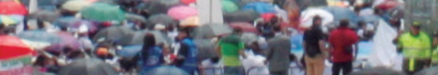

Ex

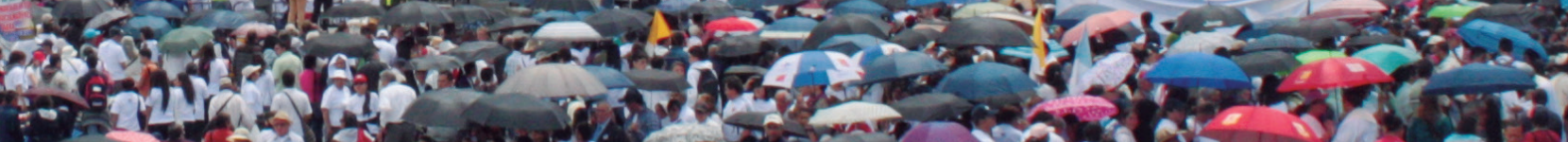

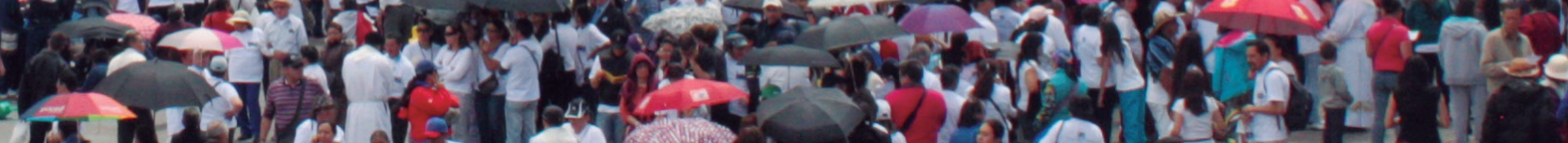

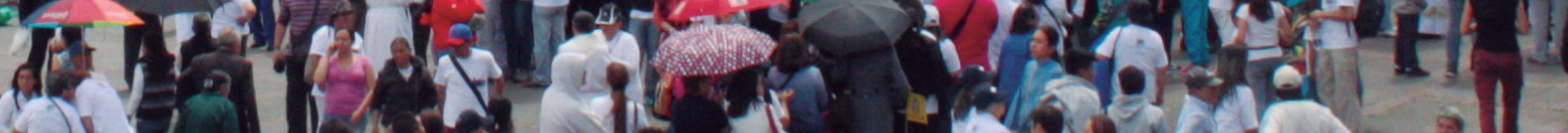

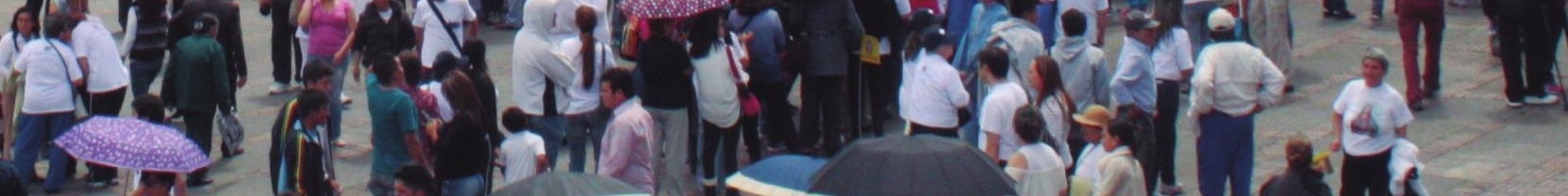
4

Acto de clausura del año jubilar de la Arquidiócesis de Bogotá. 24 de marzo de 2014. Fotografía de la Oficina Arquidiocesana de Comunicaciones. 


\section{LOS AUTORES}

Jaime Alberto Mancera Casas, Pbro.

Bachiller del Colegio Mayor de Nuestra Señora del Rosario, Filósofo y Teólogo del Seminario Mayor de San José de Bogotá y Licenciado en Teología Pastoral de la Universidad Pontificia de México. Actualmente se desempeña como Vicario Episcopal de Evangelización de la Arquidiócesis de Bogotá.

Correo electrónico: vicariadeevangelizacion@arquibogota.org.co

\section{Carlos Mario Alzate Montes, O. P.}

Bachiller en Teología de la Pontificia Universidad Javeriana, Licenciado en Filosofía y Letras y Especialista en Gerencia de Instituciones de Educación Superior de la Universidad Santo Tomás. Magíster en Historia de la Universidad Pedagógica y Tecnológica de Colombia. Realizó estudios de Doctorado en Historia de la Iglesia en la Universidad Gregoriana de Roma. Director-Fundador del Instituto de Estudios Socio-Históricos Fray Alonso de Zamora (IESHFAZ) y Rector General de la Universidad Santo Tomás.

Correo electrónico: fraycarlosmario@gmail.com

\section{Fabián Leonardo Benavides Silva}

Historiador y Magíster en Antropología de la Universidad Nacional de Colombia. Coordinador del Instituto de Estudios Socio-Históricos Fray Alonso de Zamora (IESHFAZ) de la Universidad Santo Tomás, sede principal.

Correo electrónico: fabianbenavides@usantotomas.edu.co

\section{Juan Fernando Cobo Betancourt}

Historiador, Magíster en Estudios Históricos y Doctor en Historia de la Universidad de Cambridge.

Correo electrónico: jfc37@cam.ac.uk 


\section{Estela Restrepo Zea}

Licenciada en Historia y Filosofía de la Universidad de Antioquia y Doctora en Historia de América de la Universidad Complutense de Madrid. Profesora especial, Centro de Estudios Sociales (CES), Facultad de Ciencias Humanas, Universidad Nacional de Colombia.

Correo electrónico: erestrepoz@gmail.com

Germán Pinilla Monroy, Pbro.

Licenciado en Filosofía y Teología de la Pontificia Universidad Javeriana y Magister en Teología del Instituto Católico de París. Canónigo de la Catedral de Bogotá, Capellán de la Universidad del Rosario y Director-Fundador del Centro de Estudios Teológicos (CETRE) de la misma institución educativa.

Correo electrónico: german.pinilla@urosario.edu.co

\section{Juan Carlos Lara Acosta}

Estudiante de último semestre en Historia de la Pontificia Universidad Javeriana. Auxiliar de investigación de la Vicaría de Evangelización, Arquidiócesis de Bogotá y del Instituto de Estudios Socio-Históricos Fray Alonso de Zamora (IESHFAZ), Universidad Santo Tomás.

Correo electrónico: lara.j@javeriana.edu.co

Ana María Bidegain Greising

Licenciada en Historia de la Universidad de la Republica Oriental del Uruguay, Magíster, Doctora y Postdoctora en Ciencias Históricas de la Universidad Católica de Lovaina. Profesora asociada del Departamento de Estudios Religiosos de la Universidad Internacional de Florida y Directora del Instituto de Estudios Colombianos de la misma universidad.

Correo electrónico: bidegain@fiu.edu 


\section{José David Cortés Guerrero}

Licenciado en Ciencias Sociales de la Universidad Pedagógica Nacional, Magíster en Historia de la Universidad Nacional de Colombia (Sede Bogotá), Maestro y Doctor en Historia de El Colegio de México. Profesor asociado del Departamento de Historia, Universidad Nacional de Colombia, Sede Bogotá.

Correo electrónico: jdcortesg@unal.edu.co

Jorge Enrique Salcedo Martínez, S. J.

Licenciado en Ciencias Sociales de la Universidad Pedagógica de Colombia, Teólogo y Magíster en Filosofía de la Pontificia Universidad Javeriana y Doctor en Historia de la Universidad de Oxford. Profesor asistente del Departamento de Historia, Pontificia Universidad Javeriana.

Correo electrónico: j.salcedo@javeriana.edu.co

\section{Juan Carlos Pérgolis Valsecchi}

Arquitecto de la Universidad Nacional de La Plata, Argentina y Magíster en Teoría e Historia de la Arquitectura de la Universidad Nacional de Colombia. Docente de la Universidad Católica de Colombia, Universidad Nacional de Colombia y Universidad de la Costa. Director del Centro de Investigaciones de la Facultad de Arquitectura (CIFAR), Universidad Católica de Colombia.

Correo electrónico: pergolisjuancarlos@yahoo.com

\section{Mayerly Rosa Villar Lozano}

Arquitecta de la Universidad Católica de Colombia (UCC), Magíster en Historia de la Universidad Pedagógica y Tecnológica de Colombia, Especialista en Gobierno y Gestión del Desarrollo Regional y Municipal de la UCC y en Pedagogía y Docencia Universitaria de la Universidad la Gran Colombia. Directora y docente de la Maestría en Gestión Urbana, Universidad Piloto de Colombia.

Correo electrónico: mayerly-villar@unipiloto.edu.co 


\section{Andrés Mauricio Escobar Herrera}

Historiador de la Universidad Nacional de Colombia. Docente investigador del Instituto de Estudios Socio-Históricos Fray Alonso de Zamora (IESHFAZ) de la Universidad Santo Tomás, Sede principal.

Correo electrónico: andresescobar@usantotomas.edu.co

\section{María Teresa Cifuentes Traslaviña}

Licenciada en Estudios Sociales de la Universidad Externado de Colombia y Magíster en Ciencia Política de la Universidad de los Andes. Profesora de la Universidad Distrital Francisco José de Caldas e investigadora de fenómenos sociales de las religiones.

Correo electrónico: mariatct@yahoo.com

\section{Leopoldo Prieto PÁez}

Sociólogo y Magíster en Urbanismo de la Universidad Nacional de Colombia. Coordinador de la línea en Territorio y Desarraigo del Instituto para la Pedagogía, la Paz y el Conflicto Urbano (IPAZUD), Universidad Distrital Francisco José de Caldas.

Correo electrónico: sociologoleo@gmail.com 
Esta obra se editó en Ediciones USTA, Departamento Editorial de la Universidad Santo Tomás. Se usó papel esmaltado de 150 para la carátula, propalmate de 75 gramos para páginas internas y prestige canvas de 180 gramos para guardas. Tipografías: Adobe Garamond Pro, Century Schoolbook y Avenir. Impreso por Panamericana Formas e Impresos S.A. 2015 


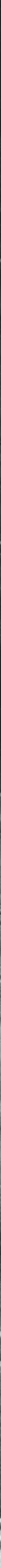

